\title{
Contratos públicos y privados de los poderes públicos desde 1845 hasta la ley 30/2007, de contratos del sector público
}

Casimiro López García

Interventor de Administración Local

Sumario: I.- EL ORIGEN DE LA DISTINCIÓN ENTRE CONTRATOS ADMINISTRATIVOS Y CONTRATOS PRIVADOS DE LA ADMINISTRACIÓN PÚBLICA.-1.1. El establecimiento de una Jurisdicción para la Administración. 1.2. El Criterio subjetivo. 1.3. La influencia de la doctrina francesa: el contrato administrativo «par nature». 1.4. La doctrina española. Identificación del contrato administrativo en el giro o tráfico de la Administración. 1.5. La cláusula obras y servicios.-II. LA CODIFICACIÓN DEL CONTRATO ADMINISTRATIVO EN ESPAÑA. 2.1. Ley 13/95, de Contratos de las Administraciones Públicas. 2.2. La Ley 53/99 de reforma de la ley 13/95, y el TR 2/2000, de 16 de junio.--III.- EL CONCEPTO DE ENTIDAD PÚBLICA EN LA JURISPRUDENCIA DEL TJCE.-3.1. La posición de la Comisión de la Unión Europea. 3.2. El concepto autónomo de entidad adjudicadora en la jurisprudencia del TJCE. 3.3. La modificación urgente del TR 2/2000, de la Ley 13/95 por el RD Ley 5/2005.-IV. LAS NOVEDADES DE LA LEY 30/2007, DE CONTRATOS DEL SECTOR PÚBLICO. 4.1. Los objetivos del Legislador: del contrato administrativo al contrato del sector público. 4.2. El ámbito subjetivo de la Ley 30/2007. 4.3. La estructura concéntrica de la Ley 30/2007. 4.4. Naturaleza y alcance de las Instrucciones de Contratación de la Ley 30/2007.-V. CONSIDERACIONES FINALES. 5.1. Necesidad de establecer una regulación homogénea de los poderes adjudicadores. 5.2. Superación y abandono de la doctrina del contrato administrativo por naturaleza en la Ley 30/2007.

\section{EL ORIGEN DE LA DISTINCIÓN ENTRE CONTRATOS ADMINISTRATIVOS Y CONTRATOS PRIVADOS DE LA ADMINISTRACIÓN PÚBLICA}

\subsection{El establecimiento de una Jurisdicción para la Administración}

La Jurisdicción Contencioso Administrativa se introduce en España por las Leyes de 2 de abril y 6 de julio de $1845^{1}$, que atribuyen la competencia para el enjuiciamiento

1 Vallejo Pousada, R., Comín Comín, F. (1991) «La reforma fiscal de Mon-Santillán desde una perspectiva histórica». Hacienda Pública Española. (MEH) Núm. extra, 1/96: 7-20. 
de los actos, acuerdos y contratos de la Administración Pública, siguiendo el modelo francés ${ }^{2}$, a unos órganos administrativos: Consejos Provinciales y Consejo Real ${ }^{3}$. La Restauración aprueba la denominada Ley Santamaría de Paredes, de 13 de septiembre de $1888^{4}$, que establece el denominado sistema «armónico», -a medio camino entre las propuestas progresistas de limitación de privilegios a la Administración propias del Sexenio liberal, que atribuyeron el conocimiento de estos asuntos a las Audiencias civiles, y la mera jurisdicción retenida en órganos administrativos-, estableciendo una solución francesa que impone un Tribunal contencioso-administrativo organizado en un Consejo de Estado y en unos Tribunales provinciales de composición mixta de funcionarios y jueces. Por supuesto, no existe un concepto de contrato administrativo ni distingo alguno entre contratos privados y administrativos de los poderes públicos 5 .

\subsection{El Criterio Subjetivo}

El origen del contrato administrativo en España se ha querido ver, precisamente, en su asignación a los órganos de la jurisdicción contencioso-administrativa. La doctrina de la época, directamente influenciada por la Doctrina Hauriou y Berthelemy, justifica la atribución de la contratación administrativa al Conseil d'Etat y a los órganos de la jurisdicción contencioso-administrativa en España, con fundamento en la distinción entre actos de autoridad, en los que el poder público actúa con imperium, y actos de mera gestión, en los que se sitúa en pie de igualdad con los particulares ${ }^{6}$. No obs tante lo cual, tanto la mens legislatoris como la doctrina, sin la menor excepción, aceptan que la naturaleza de estos contratos atribuidos ahora al conocimiento de la jurisdicción contencioso-administrativa es íntegramente de Derecho civil, cuyas normas materiales serían las únicas de aplicación?7. Por ende, el conocimiento de los con-

2 El Art. 1.1 asigna al Consejo Real la competencia para conocer de las demandas contenciosas relativas al cumplimiento, inteligencia, rescisión y efectos de los remates y contratos celebrados directamente por el Gobierno y las Direcciones Generales de los diferentes ramos de la Administración civil. Los órganos de la jurisdicción civil quedan no está para juzgar al Gobierno.

3 Nieto, A. (1966) «Sobre el origen del recurso contencioso administrativo en España». Revista de Administración Pública. (RAP). Núm. 1/1966: 27-50.

Parada Vázquez JR. (1968) «Privilegio de decisión ejecutoria y proceso contencioso». RAP. Núm. 1/1968: 1-48.

4 En vigor hasta la promulgasen de la Ley de la jurisdicción contencioso-administrativa de 27 de diciembre de 1956 y de la Ley de Conflictos Jurisdiccionales de 17 de julio de 1948.

5 Excluyendo de la vía contenciosa los recursos por excés de pouvoir francés eran las dos primeras ouvertures del recurso y vedando categóricamente el acceso a la tercera, el detournément de pouvoir, ya consolidada para entonces y a la cuarta y última, la violación de ley y de derechos adquiridos, que el Conseil d'État dejó expedita a partir del momento, 1872, en que recibió la jurisdicción delegada para resolver por sí mismo los recursos que se interponían ante él.

6 Silvela, F. (1839) «Colección de proyectos, dictámenes y leyes orgánicas o Estudios prácticos de Administración», pp. 218-219.

7 Parada Vázquez, J.R. (1961) «La lucha de las. jurisdicciones por la competencia sobre los con-

134 tratos de la Administración. Sus orígenes en el Derecho francés», en Estudios en homenaje a Jordana de Pozas. Instituto de Estudios Políticos, pp. 165 y siguientes. 
tratos celebrados por la Administración Pública se atribuyó originariamente a la jurisdicción contencioso-administrativa en atención a la personalidad pública de la Administración: «contratos celebrados por el Gobierno o por las Direcciones generales de los diferentes ramos de la Administración civil», con independencia total y absoluta de su objeto, y por supuesto de una naturaleza jurídica administrativa distinta de la civil que no se concebía ${ }^{8}$.

\subsection{La influencia de la doctrina francesa: el contrato administrativo «par nature»}

La búsqueda de una identidad propia del contrato administrativo se realizó por la doctrina francesa del «Conseil d'Etat», que abandonó el criterio sustancial de distinción entre actos de autoridad y actos de gestión, como base de atribución de los actos del poder a la jurisdicción contencioso administrativa, por el criterio de servicio público, que para la mayor parte de la doctrina tiene origen en el «arrét Blanco» de 1873"; no obstante, García de Enterría mantiene la teoría contraria: el contrato administrativo «par nature» no se ultima por el Conseil d'Etat hasta los arréts «"Théroud d'Assurance Le Soleil» y "Société de Granits porphyroides des Vosges» (1912), que coinciden con la definición de servicio público globalizadora de toda la actividad administrativa de la escuela de Burdeos, propuesta por DUGUIT: «toda actividad cuyo cumplimiento debe ser regulado, asegurado y fiscalizado por los gobernantes, porque el cumplimiento de esa actividad es indispensable para la realización y desenvolvimiento de la interdependencia social y de tal naturaleza que no puede ser asegurada completamente más que por la intervención de la fuerza gobernante».

La nueva teoría del servicio público establece una definición general y abstracta de la actividad administrativa que supone un avance sustancial en la consolidación conceptual del Derecho público. La formulación definitiva de un concepto autónomo

8 García de Enterría, E. (1963) «La figura del contrato administrativo» RAP Núm. 41. p. 100 «Sin embargo, el carácter paradigmático que hasta muy recientemente ha tenido en nuestro Derecho el Derecho administrativo francés, por una parte, teniendo en cuenta que en este Derecho existía una partición de la materia contractual administrativa entre las dos jurisdicciones; $y$, en segundo lugar, el criterio de interpretar restrictivamente lo que se proclamaba como una excepción o sustracción de la competencia natural de los Tribunales ordinarios, y más en una época en que la jurisdicción contencioso-administrativa era sumamente imperfecta (sistema de la «justicia retenida», que implicaba que los fallos procedían de la Administración activa, Consejo de Ministros y Gobernadores civiles, siendo los llamados órganos jurisdiccionales meros órganos consultivos cuyas opiniones no eran vinculantes), va a justificar el qque también entre nosotros se seleccionen unos contratos de la Administración como propios de los Tribunales contencioso-administrativos de otros que van a permanecer bajo la jurisdicción de los Tribunales ordinarios. Es así como se forja la figura de los contratos administrativos, cuya singularidad es vista en todo caso exclusivamente como una singularidad de régimen jurisdiccional’.

9 García de Enterría, E. Op. cit., núm. 8. «Es el arrét Terrie, de 1903, donde por vez primera formula el principio básico de que «todo lo que concierne a la organización y al funcionamiento de los servicios públicos propiamente dichos soit que l'Administration agisse par voie de contrat, soit qu'elle procede par voie d'autorité constituye una operación administrativa que es, por su naturaleza, del dominio de la jurisdicción administrativa». 
del contrato administrativo se debe a JÉZE ${ }^{10}$, también publicista de la Escuela de Burdeos, citado en la década de los años 50 del pasado siglo por VEDEL para reafirmarle en su condición de "padre de la teoría de los contratos administrativos, que él ha sacado casi de la nada». La distinción del contrato administrativo del contrato civil se identifica y fundamenta en las denominadas "cláusulas exorbitantes del Derecho común» (interpretación, modificación, y resolución de oficio) que se oponen al principio de igualdad de partes del contrato civil.

\subsection{La doctrina española. Identificación del contrato administrativo en el giro o tráfico de la Administración}

En España, la recepción de la doctrina francesa del servicio público vino a dar un inesperado apoyo a la propia expresión legal «obras y servicios públicos», que identificaba a los contratos de la Administración, cuya competencia se atribuía a los Tribunales contencioso-administrativos (art. 5. ${ }^{\circ}$ de la Ley de lo Contencioso de 1888 y de sus textos refundidos de 1894 y 1952). Aparecen así las primeras teorías de nuestros contratos administrativos como contratos no civiles, en virtud de la misma doctrina del servicio público, cuando hasta ese momento no se discutía la naturaleza «civil» de los contratos de la Administración pública.

Los problemas de la doctrina del servicio público, puestos de manifiesto por la crisis mundial de 1929, y acelerados por la masiva intervención del Estado en la reconstrucción europea, obligan a la doctrina de posguerra a buscar un nuevo asidero para la sustantividad del contrato Administrativo. En la España del desarrollismo, García de Enterría propone un concepto del Derecho y del contrato administrativo, como Derecho propio de las Administraciones públicas, en cuanto sujetos que modulan las instituciones jurídicas generales conforme a las exigencias de desenvolvimiento propias de las necesidades de su giro o tráfico; aceptando que esta modulación puede ser más o menos amplia en función del interés público, y teniendo en cuenta que se trata de establecer una distinción entre los contratos administrativos por naturaleza y los contratos civiles de la Administración, que una vez publicada la Ley de la Jurisdicción Contenciosa de 1956 fuera coherente con lo dispuesto en su Art. 3.

En cualquier caso, a pesar de los esfuerzos doctrinales, la distinción no tiene un alcance absoluto, puesto que todos los contratos de la Administración -hoy Arts. 20 y 21 de la Ley 30/2007, de Contratos del Sector Público (LCSP)-, necesitan recorrer la misma vía interna de formación de voluntad: previa habilitación de crédito, justificación de la contratación, aprobación del expediente de contratación con sus pliegos de condiciones; amén de seguir los mismos procedimientos de licitación para la adjudicación y formalización del contrato; equivalencia que se extiende a la capacidad de las partes, vicios del consentimiento, y supuestos de nulidad, y a la competencia de la

10 Jéze, E. (1927-34, 3 Vols.) «Les contrats administratifs. y Théorie genéral des contrats de I'Administration», tomos IV, V y VI, «Des Principes généraux da Droit administratif». París. 
jurisdicción contencioso-administrativa para conocer los recursos que puedan interponerse contra los actos de preparación y adjudicación. Por otro lado, la contratación privada no está exenta de privilegios, aunque la Administración no tenga a su disposición aquí cláusulas exorbitantes, nunca está en posición de igualdad con los particulares. Las particularidades de los procedimientos de ejecución de Sentencias relacionadas con la inembargabilidad de los fondos y caudales públicos ${ }^{11}$, más la formalidad de la reclamación administrativa previa a la vía civil -cuestiones que se mantienen en los sistemas que no reconocen la existencia de un contrato administrativo- relativizan en parte una distinción siempre sujeta a criterios de política legislativa, amén de la ineludible existencia de los denominados actos separables o previos que delimitan el objeto del contrato y establecen las reglas y los criterios de selección del contratista, que siempre serán actos de la Administración, y constituyen ahora el objeto de la armonización de los derechos nacionales por las Directivas comunitarias de contratación, relativizando de nuevo la distinción entre contratos públicos y privados de los poderes públicos.

\subsection{La cláusula obras y servicios}

Obligación, contrato y responsabilidad son instituciones básicas, centrales y comunes en los distintos sistemas jurídicos, desde su evolución y sistematización por los juristas romanos clásicos, hasta el movimiento codificador del S. XIX, sin que exista el menor atisbo de una dogmática propia del contrato administrativo como categoría jurídica independiente. Son las exigencias de garantizar el buen fin de la contratación de la Administración, las que se utilizan para justificar una modulación legal, que sólo juega en los contratos denominados por la Ley «administrativos», para introducir reglas especiales en su ejecución, cumplimiento y extinción. Son las denominadas "cláusulas exorbitantes» por la doctrina francesa"2, que junto con la vinculación al giro o tráfico de la Administración contratante pervive en la definición y justificación del contrato administrativo que establece el art. 19 de la Ley 30/2007, de Contratos

11 Mitigados por el nuevo régimen de ejecución establecido en los artículos 105 y ss. de la Ley 29/98, y por la posibilidad abierta por la doctrina del TC de embargar los bienes patrimoniales de titularidad publica.

12 La prerrogativa de poder público por excelencia con que la Administración cuenta en sus contratos administrativos es, sin duda ninguna, el privilegio de la decisión unilateral y ejecutoria, previa al conocimiento judicial, que impone al contratista el deber de su cumplimiento inmediato con la carga de impugnación contencioso-administrativa si está disconforme con su legalidad; es aquí donde precisamente se inserta la técnica contencioso-administrativa sobre el contrato que está en el origen, como sabemos, de la institución del contrato administrativo. En virtud de este formidable privilegio, la Administración puede decidir ejecutoriamente sobre: la perfección del contrato y su validez, la interpretación del contrato, la realización de las prestaciones debidas por el contratista (modo, tiempo, forma), la calificación de situaciones de incumplimiento, la imposición de sanciones contractuales en ese caso, la efectividad de éstas, la prórroga del contrato, la concurrencia de motivos objetivos de extinción del contrato (rescisión, en la terminología administrativa), la recepción y aceptación de las prestaciones contractuales, las eventuales responsabilidades del contratista durante el plazo de garantía, la liquidación del contrato, la apropiación o la devolución final de la fianza. Inversamente, el contratista no sólo está vinculado por esas decisiones a reserva de recursos ex post contra las mismas. 
del Sector Público (LCSP), por referencia a la cláusula «obras y servicios públicos», que aparece en nuestro Derecho en $1845^{13}$.

Sin embargo, sigue siendo imposible identificar el contrato administrativo con la actividad propia de la Administración, ni siquiera con la contratación de la Administración. Sólo la tutela del interés público ${ }^{14}$, en la consecución de los fines constitucionalmente previstos para la actuación de la Administración justifica la atribución de un poder exorbitante de decisión y modificación ejecutiva unilateral a favor de la Administración, en un sistema económico presidido por el principio de libertad de empresa en el marco de una economía de mercado (Art. 38 de la Constitución española), que hace imposible un reconocimiento general y absoluto de tal poder exorbitante, sino cuando se trate de la actividad genuina y esencial de la Administración. Por esta razón, se obliga a identificar una actividad negocial específica de la Administración que justifique la exclusión de los Tribunales ordinarios, y su sometimiento a la misma jurisdicción que conoce de la materia administrativa propiamente dicha, actos, órdenes y reglamentos ${ }^{15}$.

La configuración técnica del contrato administrativo tiene su origen remoto en la Francia revolucionaria, para garantizar la venta de los bienes embargados a la nobleza contrarrevolucionaria y así evitar su vuelta. En España, con la desamortización de Mendizábal y de Madoz, para movilizar los bienes en manos muertas y conseguir

13 García de Enterría, E. Op. cit. Núm. 8. Pp. 19 y 20. «Este concepto, y sobre todo el de "servicios públicos", no se refiere a algo concreto materialmente precisable, y mucho menos a una idea técnica de "servicio público» entendido en el sentido de prestación administrativa o en cualquier otro de los intentados, más bien infructuosamente, por la famosa doctrina francesa del servicio público (por ejemplo, el Tribunal Supremo ha calificado, a estos efectos de calificación contractual, de servicios públicos el alquiler de vehículos privados por la Corporación municipal —auto de 11 de febrero de 1942-, Lo que pretende decir por "servicio, público» tanto la Ley como la jurisprudencia que la ha aplicado, es la actuación propia de la Administración, singularizable en la misma como organización y sujeto singular, el cumplimiento de sus funciones y responsabilidades características, o mejor quizás, negativamente, todo lo que hace cuando no se pone en el papel funcional de un simple particular, prácticamente todo lo que hace que no sea la gestión de su dominio privado o patrimonial, o la gestión mercantil. Aquí recuperamos el sentido exacto, a mi juicio, de aquella jurisprudencia que citamos más atrás en el apartado IV, 2, que, invirtiendo el planteamiento inicial de la doctrina de los actos de autoridad y los actos de gestión, pretendía singularizar los contratos administrativos como aquellos en que la Administración obrase como poden.

14 ART. 103 de la CE de 1978, en relación con el Cap. III «De los principios rectores de la política social y económica.» Artículos 39 a 52 CE.

15 Ariño Ruiz, G. (2007) «El enigma del contrato Administrativo». RAP Núm. 176, p. 94, enero-abril de 2007 (CEPC): «Una especial importancia política para la vida del Estado. y de la sociedad, que exigía una protección especial de algunas operaciones contractuales, que no podían verse frustradas o puestas en peligro por las rigideces y el sistema de garantía que ofrecía el Derecho común. En Francia, la venta de bienes de los emigrados quería, como escribe MEILÁN, asegurar -hacer irreversible- la Revolución. En España, la venta de bienes desamortizados, que en símisma era una pura compraventa de Derecho civil, se declara contrato administrativo porque la operación desamortizadora era una operación de tal importancia política que en ningún caso el Estado quiso que pudiera resultar frustrada por una aplicación estricta de un derecho que exigía justificaciones del título de adquisición, inscripciones registrales, determinación exacta de las medidas de las fincas, régimen de retractas, etc. Estos contratos -se escribe por entonces- no constituyen una simple relación de 138 justicia conmutativa entre partes, sino que, por encima y antes que eso, el Estado persigue un fin colec la riqueza nacional, de justicia distributiva, de saneamiento financiero de la Hacienda». 
fondos para afrontar las Guerras Carlistas, -materias expulsados hoy de la contratación administrativa-. El contrato administrativo no tiene una identidad inmutable, por el contrario, la categoría de los contratos administrativos es variable y contingente, y sólo se explica y justifica por estar al servicio de la ejecución de los programas de los sucesivos Gobiernos, que se traduce en obras y servicios públicos. Su concreción requiere una decisión de política legislativa que determine las figuras contractuales (materias) en las que se establecen y reconocen los poderes de decisión unilateral de la Administración ${ }^{16}$. Desde su origen con la Escuela de Burdeos hasta la fecha, el contrato administrativo, con las particularidades de la venta de patrimonio, sigue ateniéndose a la cláusula «obras y servicios» que constituyen la nota definitoria del contrato administrativo desde el último tercio del siglo XIX hasta nuestros días, sin otra novedad que la consolidación de los nuevos postulados del Derecho comunitario en materia de procedimientos de selección y adjudicación de los contratos armonizados.

En resumen, no existe un contrato administrativo por naturaleza, la calificación de un contrato como administrativo o civil varía con el tiempo y está al servicio de los postulados ideológicos y de las necesidades que, en cada caso, se declaran de interés público: El contrato administrativo no posee una naturaleza fija o inmutable, sino una calificación jurídica dinámica. No posee una naturaleza inmutable, no es una esencia, sino una existencia histórico-jurídica ${ }^{17}$, para cuya consecución se establece un régimen jurídico especial que concede un poder de decisión y modificación unilateral a la Administración, que se equilibra con la doctrina de la revisión de precios y con la del mantenimiento del equilibrio financiero del contratista. Por el contrario, los sistemas de «common law» no conocen este régimen especial, y deben someter su actuación al derecho privado en pie de igualdad con los particulares; correspondiendo al Juez las tradicionales funciones y poderes sancionadores de la Administración en materia de orden público ${ }^{18}$.

\section{LA CODIFICACIÓN DEL CONTRATO ADMINISTRATIVO EN ESPAÑA}

La codificación del contrato administrativo en España, como la mayoría de las Leyes administrativas generales, se gesta en la década de los años 50 del pasado siglo, actuando como punta de lanza la legislación de Régimen Local, que aportará la nove-

16 Arts. 192 y ss de la Ley 30/2007, LCSP.

17 Ariño Ruiz, G. Op. cit. Núm. 15.

18 García de Enterría, E. Op. cit. Núm. 8, p. 17. «... podía perfectamente haberse atribuido la jurisdicción sobre esos contratos a la jurisdicción ordinaria (como ha ocurrido en los países que conocemos, o como pasaba antes en Derecho español para la responsabilidad civil de la Administración, o como sigue pasando también entre nosotros a propósito del dominio público, institución cuyo carácter de Derecho administrativo no es cuestionada), o incluir en la competencia de los Tribunales contencioso-administrativos a todos los contratos de la Administración y no sólo a un sector de ellos (como ocurrió en los orígenes de nuestro contencioso y propugna hoy PARADA) (38), o, en fin, trazarse la línea particional entre una y otra jurisdicción de otra manera que la establecida, y, última razón, porque en todo caso el criterio mismo de participación es, y no puede dejar de ser, como veremos, aproximativo y no riguroso y exacto». 
dad de una serie de reglamentos ${ }^{19}$, comenzando, precisamente, con él de Contratación de las Corporaciones Locales, aprobado por Decreto de 9 de enero de 1953, que incorpora inequívocamente la cláusula obras y servicios públicos en los artículos 3 y 4; y los poderes de modificación e interpretación unilateral, en los artículos 54, 99 y 100. La normativa estatal se retrasará hasta la década siguiente, en la que se aprobó la primera Ley de Contratos del Estado (Decreto 923/1965) (20 $^{2}$ con una regulación general aplicable a todos los contratos administrativos, y con el reconocimiento y regulación singular de los contratos de obras, servicios y suministros como contratos administrativos típicos, a los que se dedicaba un título específico, destacando por la regulación del contrato de obras, que se aplicaba supletoriamente al resto. La modificación aprobada por la Ley 5/1973, de 17 de marzo, y su Reglamento (Decreto 3410/1975), reconoce la existencia de contratos administrativos especiales; que tienen carácter administrativo -por declararlo así una ley o por su directa vinculación a un servicio público-, estos últimos, se regirán, en cuanto a su preparación, licitación, adjudicación, por las normas de los contratos administrativos típicos; en cuanto a sus efectos y causas de resolución y extinción, por sus normas especiales; en su defecto y por analogía por las disposiciones de la presente legislación relativa a los contratos de obras, gestión de servicios y suministros y, finalmente, por las demás normas del Derecho administrativo; supletoriamente, serán de aplicación las normas del Derecho privado21.

Junto con los contratos administrativos típicos, la Reforma de 1973 extiende su objeto a todos los contratos de contenido patrimonial vinculados a la prestación de un servicio público o que su ejecución requiera una tutela especial del interés público: la recepción de la teoría del servicio público no puede ser más explícita y completa. No obstante, aunque no se formule expresamente, desde la primera regulación, el contrato administrativo requiere la presencia de una Administración Pública. Las Empresas públicas de cualquier clase no pueden suscribir contratos administrativos en ningún caso. Por otro lado, la regulación del contrato administrativo incluye de suyo, tanto las denominadas cláusulas exorbitantes, como los procedimientos de licitación, que en nuestro Derecho, hasta la Ley 30/2007, de Contratos del Sector Público, se reducen a la subasta -sólo considera el precio- y al concurso, que juega con el concepto de oferta

19 El Reglamento de Servicios aprobado por Decreto de 17 de junio de 1955, todavía sigue en vigor en parte.

20 La Ley de 1965 y su Reglamento de 1967 abandonan la tradicional expresión «que tuvieren por finalidad obras y servicios públicos de toda especie» y destacó dos ideas para su calificación (art. 8 del Reglamento): « $10^{\circ}$ Que la prestación que se haya comprometido a entregar el particular esté directamente vinculada a las necesidades de un servicio público que requiera precisamente de aquélla para su desenvolvimiento regular; y 2. ${ }^{\circ}$ Que se haga precisa una especial tutela del interés público durante el desarrollo del contrato. Negativamente, se formula la misma idea en el artículo 11 del mismo Reglamento al definir los contratos civiles de la Administración como aquellos «en los que no concurren circunstancias que hagan preciso el ejercicio de las prerrogativas administrativas».

21 A los expresados efectos, tendrán carácter administrativo especial los siguientes contratos de la Administración: Los de contenido patrimonial, de préstamo, depósito, transporte, arrendamiento, sociedad y cualesquiera otros cuando concurra en ellos alguna de las circunstancias siguientes: «Que así lo declare expresamente una Ley. B Que esté directamente vinculado al desenvolvimiento regular de un servicio público. C que revista características intrínsecas que hagan precisa una especial tutela del interés público para el desarrollo del contrato". 
más ventajosa, sin atender exclusivamente al precio, pudiéndose decretar desierto el mismo. Todo ello al servicio de garantizar en el ámbito de la contratación administrativa los principios de publicidad y concurrencia, que se habían establecido con carácter general en la Ley contra Prácticas Restrictivas de la Competencia, de 20 de Julio de 1963.

\subsection{Ley $13 / 95$, de Contratos de las Administraciones Públicas}

Ley 13/95, de 18 de mayo, de contratos de las Administraciones Públicas mantiene el concepto amplio de servicio público, -artículos 1, 2 y $5^{22}$, y, en parte, la sistemática de la legislación administrativa de contratos públicos española, que establece una parte general común a todos los contratos y una regulación particular de cada figura, destacando la del contrato de obras, aunque ya no se aplique supletoriamente al resto de los contratos públicos. Junto a los contratos de obras, servicios y suministros, el art. 5.2 b) de la Ley 13/95, al igual que la legislación anterior, admitía la naturaleza administrativa de aquellos vinculados especialmente al giro o tráfico de la Administración o por declararlo así una Ley; estos ${ }^{23}$ contratos administrativos especiales se regían por su normativa particular y, en su defecto, por la ley de Contratos de las Administraciones Públicas, tanto en las fases de preparación y adjudicación como en la de ejecución. En los Pliegos de contratación se deberán hacer constar las prerrogativas que se atribuye y reserva la Administración en materia de interpretación, modificación y resolución.

En la Ley de 1995, los contratos patrimoniales de compraventa, permuta arrendamiento y demás negocios análogos sobre bienes inmuebles, más la categoría 6 de su artículo 206 (contratos bancarios y de seguros), todos los contratos referentes a la creación artística o literaria, y los de espectáculos estaban configurados como contratos privados, por muy vinculados que puedan estar a la prestación de un servicio público; excepción y exclusión que sembrará de dudas la naturaleza jurídica de los contratos suscritos por las sociedades municipales de gestión urbanística en materia de suelo y ordenación urbana24.

2251 . Los contratos que celebre la Administración tendrán carácter administrativo o carácter privado.

2. Son contratos administrativos:

«a) Aquellos cuyo objeto directo, conjunta o separadamente, sea la ejecución de obras, la gestión de servicios públicos y la realización de suministros, los de consultaría y asistencia o de servicios, excepto los contratos comprendidos en la categoría 6 del artículo 206 referente a contratos de seguros y bancarios y de inversiones y, de los comprendidos en la categoría 26 del mismo artículo, los contratos que tengan por objeto la creación e interpretación artística y literaria y los de espectáculos.

b) Los de objeto distinto a los anteriormente expresados, pero que tengan naturaleza administrativa especial por resultar vinculados al giro o tráfico específico de la Administración contratante, por satisfacer de forma directa o inmediata una finalidad pública de la específica competencia de aquélla o por declararlo así una ley».

23 Desaparece la referencia al supuesto de los contratos que requieran una especial tutela del interés público.

24 El aspecto que me propongo desarrollar, al hilo de una crónica de las Conclusiones de la Abogado General (AG) Sra. Juliane Kokot, presentadas el día 15 de junio de 2006 en el asunto C-220/05, Centro de Ocio de la ciudad de Roanne, es el de la tendencia a la consolidación de una apertura del mercado de los contratos públicos que tienen por objeto la ejecución del planeamiento, bien se trate de ejecutar 
La Ley 13/95, de 18 de mayo, supera la situación de urgencia y provisionalidad generada por la obligada adaptación de la Ley de Contratos del Estado a las necesidades que supuso la incorporación de España a la Unión Europea, que obligó a la aprobación de una adecuación urgente, aprobada por el Real Decreto Legislativo, 931/86, de 2 de mayo, dictado al amparo de las competencias normativas del Estado establecidas en el artículo 149.1.18 de la CE de 1978, y otros títulos competenciales del mismo artículo, con la finalidad de incorporar al Derecho español las Directivas Comunitarias del Consejo en materia de contratación, 92/50/CEE, de 18 de junio; y las Directivas 93/36/ y 93/37 CEE, de 14 de junio; que refuerzan el concepto y el alcance de la armonización de los procedimientos de contratación pública en todo el ámbito de la Unión Europea al servicio de la efectividad los grandes principios de los Tratados de la Unión: libertad de acceso, igualdad de trato, no discriminación, y libertad de establecimiento; sin embargo, mantiene los procedimientos tradicionales de subasta y concurso, que no coinciden con la regulación armonizada.

Las nuevas Directivas abren la discusión sobre el alcance del concepto de entidad adjudicadora pública sujeta a la regulación armonizada, y en especial sobre el alcance de la forma (pública o privada) en los organismos creados por una Entidad Pública para satisfacer una necesidad de interés general que no tenga naturaleza mercantil, siempre que además se controle su gestión, se nombre a más de la mitad de los miembros de sus órganos de gobierno o se financie su actividad. En este concreto aspecto, la Ley 13/95, vigente hasta uno de mayo de 2008, incorpora un concepto formal de organismo público: en principio, de acuerdo con su Disposición Adicional Sexta (DA), las empresas mercantiles de titularidad pública, aunque tengan por objeto el servicio público, y aunque constituyan un modo de gestión de un servicio público -artículo 85 de la Ley $7 / 85$, de Bases del Régimen Local- quedan extramuros de la nueva Ley y su contratación se rige íntegramente por el Derecho privado, sólo les resultan de aplicación los principios de publicidad y concurrencia, exclusión que se denunció por la Comisión de la Unión Europea ante el TJCE, por incumplimiento de la obligación de incorporación del concepto de Poder Adjudicador que establece el Art. 1.3 b) de la Directiva 93/3725.

\subsection{La Ley $53 / 99$ de reforma de la ley $13 / 95$, y el TR $2 / 2000$, de 126 de junio}

La reforma de la Ley de Contratos de las Administraciones Públicas se introduce por la Ley 53/99, de 28 de diciembre, al objeto de incrementar la concurrencia y au-

obras de urbanización o equipamientos de infraestructura urbana. A estos efectos, ténganse en cuenta las modificaciones que introdujeron, sucesivamente, a raíz de determinadas Sentencias del TJCE que condenaron al Reino de España por defectuosa transposición de las Directivas comunitarias sobre contratación pública, la Ley 62/03, de 30 de diciembre, y el Real Decreto Ley 5/2005, de 11 de marzo, en, por una parte, la Disposición adicional decimosexta y en, por otra parte, los artículos 2.1 y Disposición adicional sexta del Texto Refundido de la Ley de Contratos de las Administraciones Públicas (LCAP), aprobado mediante Real Decreto Legislativo 2/2000, de 16 de junio.

25 Aragón Román, A. (2008) «Las sociedades urbanísticas locales ante la Ley 30/2007». El Consultor de los Ayuntamientos (EC). P. 1973. 
mentar la transparencia y objetividad en los procedimientos de adjudicación en la contratación administrativa ${ }^{26}$; modificando las cuantías, y reduciendo los plazos de publicación cuando no sea preceptivo el anuncio en el DOCE. Con el fin de incorporar las disposiciones de la Directiva 97/52/CE, del Parlamento y del Consejo, cuyas modificaciones debieron incorporarse antes de 13 de octubre de 1999; entre otras novedades, suprime el contrato de trabajos no habituales, y admite, con ciertos límites, las figuras de los contratos de arrendamiento financiero y de arrendamiento con opción de compra, superando el obstáculo que para su utilización suponía la prohibición de precio aplazado, y los contratos con empresas de trabajo temporal, con lo cual se pretende dotar a las Administraciones públicas de figuras y modalidades contractuales de normal utilización en el tráfico contractual privado ${ }^{27}$.

En cuanto a la contratación patrimonial, se ratifica la naturaleza privada de los contratos de compraventa y otros patrimoniales, que siguen rigiéndose, en cuanto a su preparación y adjudicación, por la legislación patrimonial aplicable en las distintas administraciones públicas, o en su defecto, por la propia legislación de contratos, artículo 9.1, el apartado 3 mantiene, no obstante, la dualidad de jurisdicciones establecida por la Ley $13 / 95^{28}$. En cuanto a las sociedades mercantiles de titularidad pública,

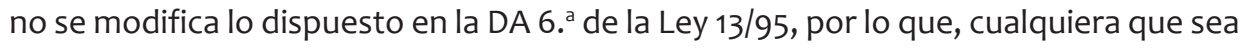
su naturaleza incluida la condición de medio propio o de poder adjudicador, siguen fuera de la Ley y sólo les resultan de aplicación sus principios.

26 Limitando las modificaciones de unidades del contrato, y con la supresión de la posibilidad de prórrogas tácitas en los contratos administrativos y la reducción de la duración de los contratos de gestión de servicios públicos según sus diferentes tipos y a dos años del plazo máximo de duración de los contratos de consultoría y asistencia y los de servicios, con lo que se trata de favorecer la concurrencia en estos contratos; la regulación más adecuada de los supuestos de baja temeraria, introduciendo su posible apreciación en los concursos y evitando la realización por sociedades pertenecientes a un mismo grupo de prácticas que pueden desvirtuar la competencia; la exigencia de un mayor rigor en los proyectos y el establecimiento de un régimen más estricto para la contratación conjunta de elaboración del proyecto y ejecución de las obras correspondientes, así como para la posible aplicación del procedimiento negociado en la adjudicación de obras complementarias y la introducción de exigencias de mayor diligencia por la Administración en la expedición de certificaciones y en el abono de liquidaciones.

27 La DF Única de la Ley 53/99, autoriza al Gobierno para aprobar un Texto Refundido de la Ley $13 / 95$, al objeto de regularizar, armonizar y aclarar las disposiciones legales vigentes, e incorporar la Decisión de la Comisión Europea (1999/C 379/08), que se aprobó como Decreto Legislativo 2/2000, de 16 de junio, incorporaba los nuevos umbrales de contratación armonizada, pero no extendió a las empresas públicas constituidas en forma de sociedad privada, los preceptos de la Ley sobre régimen de selección y adjudicación, que se reservan para los organismos y entidades de Derecho público.

28 Artículo 9. Régimen jurídico de los contratos privados.

«1. Los contratos privados de las Administraciones públicas se regirán en cuanto a su preparación y adjudicación, en defecto de normas administrativas específicas, por la presente Ley y sus disposiciones de desarrollo y en cuanto a sus efectos y extinción, por las normas de derecho privado. A los contratos de compraventa, donación, permuta, arrendamiento y demás negocios jurídicos análogos sobre bienes inmuebles, propiedades incorporales y valores negociables se les aplicarán, en primer lugar, en cuanto a su preparación y adjudicación, las normas de la legislación patrimonial de las correspondientes Administraciones públicas.

3. El orden jurisdiccional civil será el competente para resolver las controversias que surjan entre las partes en los contratos privados. No obstante, se considerarán actos jurídicos separables los que se dicten en relación con la preparación y adjudicación del contrato y, en consecuencia, podrán ser impugnados ante el orden jurisdiccional contencioso-administrativo de acuerdo con la normativa reguladora de dicha jurisdicción». 


\section{EL CONCEPTO DE ENTIDAD PÚBLICA EN LA JURISPRUDENCIA DEL TJCE}

El Tribunal de Luxemburgo, desde principios de los años 90 del pasado siglo, coincidiendo con la entrada en vigor del Tratado de Maastricht, y especialmente, desde la aprobación del Pacto de Estabilidad y Crecimiento, a instancia de las sucesivas denuncias de la Comisión Europea, queda emplazado a establecer una doctrina sobre el alcance subjetivo de las Directivas 36, 37 y 38 de 1992, sobre procedimientos de coordinación de la adjudicación de los contratos de obras, servicios y suministros de las Administraciones de los Estados miembros; sobre la aplicación o excepción de éstos procedimientos a las relaciones entre las Administraciones Públicas y sus entidades de gestión de servicios públicos; y sobre las relaciones financieras -régimen de ayudas públicas- entre las Administraciones Públicas y las empresas públicas, empresas con derechos especiales o exclusivos, más las propiamente financieras y manufactureras dependientes de los Estados y de sus entes territoriales, con la finalidad de determinar las distintas situaciones posibles que se pueden presentar, para declarar la compatibilidad con el Derecho comunitario de las ayudas financieras, y las contrataciones directas de los Entes públicos con sus empresas dependientes; y para establecer la sujeción o exclusión de las empresas de titularidad pública a las Directivas de contratación, sin perjuicio de su forma privada, cuando en realidad funcionen como si de órgano o ente administrativo se tratara ${ }^{29}$.

\section{EI TJCE establece una doctrina completa sobre los siguientes conceptos:}

Medio propio, entidades privadas que trabajan exclusivamente para la Administración que las ha creado y sobre las que dispone de un poder equivalente al que tiene sobre sus propios órganos ${ }^{30}$.

29 La doctrina del medio propio o técnico y el concepto funcional de poder adjudicador, junto con la formulación de nuevas Directivas 17 y 18/2004/CE, en materia de coordinación de procedimientos de contratación de las Administraciones Públicas; y la Directiva 111/2006/CE, en materia de relaciones financieras de los Estados con sus empresas públicas, constituyen el fruto del enorme esfuerzo realizado por todas las instituciones comunitarias para establecer conceptos y procedimientos, que con independencia de la forma y de los distintos sistemas jurídicos de los Estados, sirvan a la efectividad de los principios de libre competencia, libertad de establecimiento, no discriminación, libertad de acceso, y trasparencia de las relaciones entre las Administraciones Públicas y sus empresas de interés económico general, o las meramente financieras y manufactureras; estableciendo nuevas obligaciones en materia de identificación de los distintos Entes y Empresas de titularidad pública en todas y cada una de ellas en las distintas Directivas.

30 La SJJCE, de 18 de noviembre de 1999 (c-107/98) conocida comúnmente como Sentencia Teckal. Ante la impugnación que una empresa privada realizó del contrato entre un Ayuntamiento y una Azienda consorziale, el Tribunal admitió que es posible excluir la aplicación de las directivas de contratos públicos cuando se contrata con una entidad: «en el supuesto de que, a la vez, el ente territorial ejerza sobre la persona de que se trate un control análogo al que ejerce sobre sus propios servicios y esta persona realice la parte esencial de su actividad con el ente o los entes que la controlan».

El segundo requisito es que preste todos sus servicios a la Administración de la que depende, para que el contrato sea doméstico, la actividad ha de quedar en casa. Si la sociedad interviene en el mercado, mantiene fructíferas relaciones económicas en el tráfico mercantil, está revelando su condición de empresarial y, por tanto, ha de reconocerse ese papel comercial y tratarla como al resto de las entidades. O mejor dicho, que el resto de las empresas comerciales puedan exigir el mismo trato que esa sociedad «pública» de clara vocación empresarial. 
Servicio de interés económico general, entidad o empresa que, por razones de interés público, tiene concedidos derechos especiales o exclusivos para la gestión o prestación en monopolio de un determinado servicio

Entidad adjudicadora, o poder adjudicador, para identificar un concepto funcional de Administración Pública, que parte del dominio financiero de la entidad y de la posibilidad de nombramiento o remoción de los consejos de administración de las entidades y empresas de plena titularidad pública constituidas bajo el manto del Derecho privado.

\subsection{La posición de la Comisión de la Unión Europea}

La Jurisprudencia comunitaria ${ }^{31}$, para posibilitar y hacer efectiva una interpretación autónoma y uniforme en todos Estados, establece un concepto funcional de organismo público que requiere la concurrencia de los tres requisitos acumulativos que enuncia el artículo 1, letra b), párrafo segundo, de las Directivas 93/36 y 93/3732; sin que el estatuto de Derecho privado constituya un obstáculo que pueda excluir por sí solo su calificación como poder adjudicador en el sentido de estas Directivas (sentencia de 15 de mayo de 2003, Comisión/España, apartados 54, 55 y 60), y sin que la ausencia de referencia expresa a la categoría específica de empresas públicas tenga entidad para dudar sobre el alcance de esta doctrina33.

La denuncia presentada por la Comisión contra España en el asunto SIEPSA sostiene que la normativa española incorpora de manera incorrecta el concepto de entidad adjudicadora que figura en el artículo 1, letra b), de las Directivas 93/36 y 93/37, ya que excluye de su ámbito de aplicación a las entidades de Derecho privado, cuando

31 Por escrito presentado en la Secretaría del Tribunal de Justicia el 18 de julio de 2000, la Comisión de las Comunidades Europeas interpuso, con arreglo al artículo 226 CE, recurso ante el TJCE con objeto de que se declare el incumplimiento por el Estado español de la obligación de incorporar el concepto de organismo de Derecho público que figura en el Art. 1.3.b) de la Directiva 93/37CEE. La denuncia se gesta y formula con ocasión de la licitación relativa a la ejecución de las obras del Centro Educativo Penitenciario Experimental de Segovia convocada por la Sociedad Estatal de Infraestructuras y Equipamientos Penitenciarios, S.A. (en lo sucesivo, «SIEPSA»); que para la Comisión responde a la definición de entidad adjudicadora del artículo 1, letra b), de la Directiva 93/37/CEE del Consejo, y para el Gobierno de España a la entidad mercantil.

32 SS Mannesmann Anlagenbau Austria y otros, Apts. 20 y 21; de 12 de diciembre de 2002, Universale-Bau y otros, C-470/99, Rec. p. 1-11617, apartados 51 a 53; de 15 de mayo de 2003, Comisión/España, C-214/00, Rec. p. 1-4667, apartados 52 y 53, y de 16 de octubre de 2003, Comisión/España, C-283/00, Rec. p. 1-11697, apartado 69). Posición que se mantiene en posteriores sentencias, en las que, siendo empresas públicas, se entra a valorar si se encuentran sometidas a las Directivas de contratación pública: de 17 de diciembre de 1998, de 1 de febrero de 2001, de 10 de mayo de 2001, de 27 de febrero de 2003, de 15 de mayo de 2003 , de 22 de mayo de 2003.

33 Fuertes López, M. (1999) «Personificaciones públicas y contratos administrativos. La última Jurisprudencia del Tribunal de Justicia de la Comunidad Europea». Revista de Estudios de la Administración Localy Autonómica (RELA) Núm. 279, pp. 25 a 34.

Alonso García, R. (1990) «La ejecución normativa del Derecho comunitario europeo en el ordenamiento español» $R A P$, núm. 121 . 
éstas pueden cumplir los requisitos enunciados en el artículo 1, letra b), párrafo segundo, guiones primero, segundo y tercero, de dichas Directivas, sin que un eventual ánimo de lucro pueda empañar esta realidad ${ }^{34}$. En definitiva, la Directiva 93/37 no requiere la existencia de pérdidas para que el organismo, empresa o entidad de interés general no tenga naturaleza o carácter industrial o mercantil. SIEPSA, sin perjuicio de su forma privada, es un ente creado para satisfacer necesidades de interés general, que no tienen carácter industrial o mercantil. Interpretación que confirma la lectura de sus Estatutos, que sitúan a la sociedad en el ámbito y bajo la dirección de las órdenes y directrices de la Dirección General de la Administración Penitenciaria, que controla y autoriza tanto la enajenación de bienes inmuebles como el empleo del importe de sus rentas.

\subsection{El concepto autónomo de entidad adjudicadora en la jurisprudencia del TJCE}

El TJCE entiende que el concepto organismo público del artículo 1, letra b), párrafo segundo, de la Directiva 93/37, sólo requiere haberse creado para satisfacer directa y específicamente necesidades de interés general que no tengan carácter industrial o mercantil, por el ente público del que dependa su dirección, financiación y actividad, con absoluta independencia de su forma público o privada de constitución. En cuanto a la naturaleza mercantil de la actividad, -en el sentido del artículo 1, letra b), de las Directivas comunitarias relativas a la coordinación de los procedimientos de adjudicación de contratos públicos-, para el TJCE no tienen carácter industrial o mercantil aquellas necesidades que, por una parte, no se satisfacen mediante la oferta de bienes o servicios en el mercado y, por otra, el Estado decide satisfacerlas por sí mismo por razones de interés general o respecto de las cuales quiere conservar una influencia determinante ${ }^{35}$. Sin una referencia expresa a las definiciones contables del SEC, y sin que puedan identificarse plenamente los conceptos contables de sociedades públicas de mercado y de no mercado, a efectos de la imputación de sus resultados a las cuentas publicas, -sólo son sociedades de mercado las que obtienen más del $50 \%$ de sus recursos con cargo al mercado-, la doctrina del poder adjudicador utiliza a la postre el mercado como criterio de distinción entre poderes adjudicadores -sujetos a las Directivas de contratación- y el resto de las sociedades mercantiles de titularidad pública: Sin participar en el mercado ni asumir riesgos no existe empresa ni actividad mercantil posible.

A estos efectos, la existencia de una necesidad de interés general que no tenga carácter industrial o mercantil tiene que apreciarse teniendo en cuenta todos los antecedentes y circunstancias jurídicas y políticas que rodean la creación de cada entidad, y las condiciones financieras en que ejerce su actividad. En particular, la falta o

34 El hecho de que SIEPSA actúe eventualmente con ánimo de lucro no es incompatible con la satisfacción de un interés general que no tenga carácter industrial o mercantil.

35 STJCE Adolf Truley, apartado 50, y de 22 de mayo de 2003, S. Korhonen y otros, C-18/01, Rec. p. I-0000, apartado 47). 
ausencia de mercado, la falta de ánimo de lucro como objetivo principal, la no asunción de los riesgos derivados de dicha actividad tanto por la sociedad como por los miembros de su Consejo de Administración, así como la eventual financiación pública de la actividad de que se trate, directamente o través de algún sistema de compensación de pérdidas, son circunstancias determinantes para esta calificación ${ }^{36}$. De acuerdo con esta serie de razonamientos, en el caso SIEPSA, el TJCE entiende que su creación y establecimiento responde a una necesidad pública exclusiva: la ejecución de programas y actuaciones previstos en el Plan de Amortización y Creación de Centros Penitenciarios, por lo que es manifiesto que está encargada de la ejecución del Plan de Amortización y Creación de Centros Penitenciarios aprobado por el Consejo de Ministros, programas de manifiesto interés general, no mercantil; sin que además exista mercado posible en una materia planificada, controlada y financiada por el Estado, del que SIEPSA es un mero instrumento, y por ende no puede tener naturaleza mercantil en ningún caso, dado que no existe libre competencia con otros operadores económicos ${ }^{37}$. Esta conclusión se corrobora, con la evidencia de que será el Estado español el encargado de soportar todos los riesgos económicos de la empresa. En definitiva, no actúa en condiciones de igualdad y sin prerrogativas propias del sector público; por lo que la adopción de la organización y las técnicas del Derecho privado es irrelevante, al dirigir toda su actividad a la ejecución directa de una función pública, y haberse creado con esta finalidad específica de medio técnico o propio del Estado. En consecuencia, debe calificarse de organismo de Derecho público en el sentido del artículo 1, letra b), párrafo segundo, de la Directiva 93/37 y, por tanto, como entidad adjudicadora está obligada a aplicar los procedimientos de adjudicación de las Directivas comunitarias a todos los contratos públicos de obras convocados por dicha sociedad, en cuanto estén sujetos a armonización.

\subsection{La modificación urgente del TR 2/2000, de la Ley 13/95 por el RD Ley 5/2005}

La exposición de motivos de la RD Ley 5/2005, de 11 de marzo, de Reformas Urgentes para el Impulso a la Productividad y para la Mejora de la Contratación Pública, entre otras razones, justifica la obligada urgencia de la reforma legislativa en la STJ-

36 STJCE de 22 de mayo de 2003; STJCE de 13 de diciembre de 2007 (Bayerischer): «A fin de evaluar si dicha necesidad carece de carácter industrial o mercantil, corresponde al órgano jurisdiccional nacional apreciar las circunstancias que rodearon la creación de la sociedad y las condiciones en que ejerce su actividad, incluidas, en particular, la falta de ánimo de lucro como objetivo principal, la no asunción de los riesgos derivados de dicha actividad así como la eventual financiación pública de la actividad de que se trate. Es más, afirma el TICE que la circunstancia de que los edificios que se vayan a construir se arrienden solamente a una empresa no desvirtúa la condición de organismo de Derecho público del arrendador, siempre que se haya acreditado que éste satisface una necesidad de interés general que no tenga carácter industrial o mercantil».

37 Los Estatutos de dicha sociedad aclaran que tiene por objeto la adquisición de inmuebles para la instalación de nuevos centros, la promoción y la ejecución de obras de urbanización y construcción o incluso la enajenación de las instalaciones desafectadas, en cuanto medios necesarios para ejecutar la política penitenciaria del Estado. Conclusión viene corroborada por el hecho de que SIEPSA registró pérdidas financieras considerables durante los ejercicios 1997 y 1998. 
CE, de 13 de enero de 2005, (C 84-03), que declaraba el incumplimiento de España de las obligaciones que le incumben en virtud de las Directivas del Consejo, 93/36/CEE, y 93/37/CEE del Consejo, de 14 de junio de 1993, sobre Coordinación de los Procedimientos de Adjudicación de Contratos Públicos, por excluir el Art. 1.3 del ámbito de aplicación del Texto Refundido de la Ley de Contratos de las Administraciones Públicas, a las entidades de Derecho privado que reúnan los requisitos recogidos en el artículo 1 , letra b), párrafo segundo, guiones primero, segundo y tercero, de cada una de las mencionadas Directivas, por excluir también de forma absoluta del ámbito de aplicación del Texto Refundido -Art. 3, apartado 1, letra c)- los convenios de colaboración que celebren las Administraciones Públicas con las demás entidades públicas, cuando por razón de su objeto e importe se trate de contratos sujetos a regulación armonizada, y por autorizar en los artículos 141, letra a), y 182, letras a) y g), del Texto Refundido $2 / 2000$, el recurso al procedimiento negociado en dos supuestos que no están contemplados en las citadas Directivas.

Para dar cumplimiento a la Sentencia, la reforma somete la actividad de las fundaciones del sector público, los convenios firmados con otras Administraciones al ámbito subjetivo del DL 2/2000, de 16 de junio, y a las sociedades de titularidad pública al ámbito de la Directiva, en cuento tengan la naturaleza de medio propio, Art. 1, apartado 3: «Deberán asimismo ajustar su actividad contractual a la presente Ley los organismos autónomos en todo caso y las restantes entidades de derecho público con personalidad jurídica propia, vinculadas o dependientes de cualquiera de las Administraciones públicas, siempre que en aquéllas se den los siguientes requisitos:

a) Que hayan sido creadas para satisfacer específicamente necesidades de interés general que no tengan carácter industrial o mercantil.

b) Que se trate de entidades cuya actividad esté mayoritariamente financiada por las Administraciones públicas u otras entidades de derecho público, o bien, cuya gestión se halle sometida a un control por parte de estas últimas, o cuyos órganos de administración, de dirección o de vigilancia estén compuestos por miembros más de la mitad de los cuales sean nombrados por las Administraciones públicas y otras entidades de derecho público.»

En definitiva, en el RD Ley 5/2005 se incorpora el concepto de entidad adjudicadora, con una nueva redacción del art. 2.1 del TR 2/2000, que incluye a todas las sociedades del Art. 166 de la Ley 33/2003 -y a sus equivalentes en las Comunidades Autónomas y en las Entidades Locales- en cuanto se hayan sido creado para satisfacer una necesidad de interés general de carácter no mercantil, pero sólo en cuanto nos encontremos por encima de los umbrales cuantitativos establecidos para los contratos armonizados por las Directivas comunitarias. Para el resto de los contratos de estos poderes adjudicadores y para las sociedades públicas de mercado, se mantiene la dicción de su DA 6. a limitada a la aplicación de los principios. Los convenios interadministrativos se sujetan a los procedimientos de selección y adjudicación de las Direc148 tivas de Contratación, siempre que se trate de contratos sujetos a regulación armoni- 
zada, salvo que se trate de supuestos de encomienda de gestión, a pesar de encontrarse pendiente de fallo el asunto TRAGSA ${ }^{38}$.

\section{LAS NOVEDADES DE LA LEY 30/2007, DE CONTRATOS DEL SECTOR PÚBLICO}

\subsection{Los objetivos del Legislador: del contrato administrativo al contrato del sector público}

La transposición de la nueva Directiva de Contratación, 2004/18/CE, se realiza con notorio retraso por la Ley 30/2007, de 30 de octubre, de Contratos del Sector Público (LCSP) ${ }^{39}$, mucho más extensa y compleja que sus antecedentes. A pesar de las críticas generalizadas al Proyecto presentado por el Gobierno en las Cortes Generales, la nueva Ley no se limita a una nueva modificación de la Ley 13/95, que con ligeros retoques incorpore los procedimientos de selección armonizados por la nueva Directiva. Se busca una modificación sustancial de nuestro sistema de contratación pública, que supere definitivamente el ámbito objetivo del contrato administrativo, pensado y destinado para su aplicación por la Administración Pública en sentido estricto, para definir unas figuras contractuales comunes y de aplicación general a todo el sector público, -incluidos los poderes adjudicadores y los medios propios, tímidamente abordados por el RD Ley 5/2005, y las propias empresas de mercado-, modulando la intensidad de su aplicación en función de la naturaleza administrativa o mercantil de las sociedades y entidades de todo el sector público del Estado español.

En este sentido, la finalidad principal declarada por el Legislador en el artículo 1 de la Ley ${ }^{40}$ es la regulación integral de los procedimientos de selección y de adjudicación de toda la contratación de los entes del sector público, de acuerdo con los principios de la Directiva 18/2004/CE: concurrencia, publicidad, transparencia, igualdad de acceso, y no discriminación, al servicio de los objetivos de estabilidad presupuestaria impuestos por el Pacto de Estabilidad y Crecimiento de 1997. A tal efecto, los nuevos procedimientos armonizados de licitación y adjudicación de los contratos (abierto, restringido y negociado), constituyen el centro de gravedad de la nueva Ley, y despla-

38 Exclusión que tenía sus riesgos cuando estaba pendiente de Sentencia la demanda interpuesta por la Comisión contra TRAGSA, que terminó desestimada por el TJCE.

39 El plazo venció con fecha, 1 de febrero de 2006.

40 Artículo 1. Objeto y finalidad. "La presente Ley tiene por objeto regular la contratación del sector público, a fin de garantizar que la misma se ajusta a los principios de libertad de acceso a las licitaciones, publicidad y transparencia de los procedimientos, y no discriminación e igualdad de trato entre los candidatos, $y$ de asegurar, en conexión con el objetivo de estabilidad presupuestaria y control del gasto, una eficiente utilización de los fondos destinados a la realización de obras, la adquisición de bienes y la contratación de servicios mediante la exigencia de la definición previa de las necesidades a satisfacer, la salvaguarda de la libre competencia y la selección de la oferta económicamente más ventajosa. 2.- Es igualmente objeto de esta Ley la regulación del régimen jurídico aplicable a los efectos, cumplimiento y extinción de los contratos administrativos, en atención a los fines institucionales de carácter público que a través de los mismos se tratan de realizar». 
zan definitivamente la denominada parte general del contrato administrativo regulada en las leyes de 1965 y de 1995; al mismo tiempo que suponen un cambio conceptual y terminológico con el abandono definitivo de los tradicionales procedimientos de subasta y concurso, que habían presidido la licitación y selección de nuestra contratación pública, y todavía siguen vigentes en la contratación patrimonial, al no haberse adaptado la Ley 33/2003, de Patrimonio de las Administraciones Públicas, a los nuevos procedimientos armonizados de selección, de aplicación supletoria (Art. 4.2) a la contratación patrimonial y al resto de los negocios excluidos de su ámbito en el listado del Art. 4.1 de la LCSP.

La regulación del contrato administrativo aparece en el párrafo $2 .^{\circ}$ del Art. 1, como objetivo subordinado y meramente secundario, que una vez más sólo se justifica por garantizar una protección especial de los fines institucionales de la Administración contratante. Se abandona definitivamente la dogmática tradicional del contrato administrativo como eje de la contratación pública, que se construye en la nueva Ley sobre el concepto de contratos del sector público con absoluta independencia de su naturaleza civil o administrativa. El Capítulo I del Título Preliminar de la LCSP, «Contratos del Sector Público», artículos 5 a 12, define al margen de su naturaleza y por referencia a la presencia de una entidad del sector público los distintos tipos de contratos sujetos a esta Ley: obras, concesión de obra pública, servicios, suministros, servicios públicos, y contratos de colaboración entre el sector público y privado; a los que se deben añadir los contratos mixtos, y el contrato subvencionado. El contrato administrativo pierde así su tradicional predominio legal y teórico sobre la contratación pública; tanto por la absoluta preponderancia que concede la LCSP a la recepción de la regulación armonizada de los procedimientos de selección y adjudicación de los contratos del sector público, que se incorporan por separado para servir de referencia y guía de toda la contratación de las Administraciones y de los distintos entes públicos y privados del sector público, -y no como procedimientos de adjudicación de los contratos administrativo- como por la definición de los tipos y de los elementos esenciales de los contratos públicos con independencia del contrato administrativo.

La LCSP destina la Sección 2. a de este capítulo I . . artículos 13 a 17, a definir los contratos sujetos a armonización por el Derecho comunitario, categoría que constituye el núcleo de la nueva regulación, y el objeto obligatorio de los procedimientos de selección y adjudicación establecidos por la Directiva 18/2004/CE, para todos los poderes adjudicadores, con independencia de su forma de constitución ${ }^{41}$. En los contratos sujetos a armonización, la recepción de la Directiva es imperativa en su integridad, con independencia la naturaleza administrativa o privada que el ordenamiento de cada Estado atribuya a los contratos de las Administraciones Públicas, y con independencia de la forma de constitución elegida. Los contratos sujetos a regulación armonizada, por los importes y según la clase y objeto que se incorpora en el Anexo

41 Moreno Molina, J.A. (2009) «“Un mundo para Sara.” Una nueva categoría en el Derecho español de la contratación pública: los contratos sujetos a regulación armonizada». RAP. Núm. 178. Pp. 175-213. 
II de la LCSP, en todo caso, sólo pueden tramitarse y adjudicarse por los procedimientos que se establecen en la Directiva 18/2004/CE ${ }^{42}$.

Para terminar, los contratos administrativos y los contratos privados se definen en la Sección $3 .^{a}$, con independencia de su naturaleza y objeto (obras, servicios y suministros), que ya se ha definido en las secciones anteriores para todo el sector público, por la intervención o no de una Administración Pública, con las excepciones que se establecen ${ }^{43}$ en el Art. 20 para los contratos privados de la Administración. No obstante, a pesar de la manifiesta postergación de la figura del contrato administrativo en la nueva Ley, -ya no anuda los procedimientos de selección del contratista a la existencia de un contrato administrativo o a la presencia de la Administración ni establece los contratos administrativo como referencia de la contratación pública-, los procedimientos armonizados de selección y adjudicación del contratista, y todo el articulado de la Ley 30/2007 solo se aplican en su integridad a la Administración, y por ende solo tiene aplicación plena cuando se trate de contratos administrativos.

Sin embargo, hay que reconocer que la LCSP dibuja un cambio estructural en la regulación de la contratación pública, que supone una ruptura brusca con nuestra tradición legislativa en materia de contratos públicos, hasta ahora basada en una organización bipolar construida alrededor de una parte general, compuesta por normas aplicables a todos los contratos administrativos, y una parte especial, en la que se recogían las peculiaridades de régimen jurídico de los contratos administrativos típicos, vigente en la Ley 13/95. El cambio viene obligado por la necesidad de ajustar su ámbito material de aplicación al objeto de las Directivas comunitarias, con la plena recepción de los contratos armonizados y de sus procedimientos de selección como centro de la nueva regulación, que se regulan por separado para evitar su confusión con una regulación interna y propia del Estado español en materia de contratos del sector público. Por otro lado, se establece por primera vez una regulación de los procedimientos de selección y adjudicación de los contratos del sector público empresarial -hasta la fecha, tradicionalmente, remitidos al Derecho privado- que debe servir de verdadera legislación común o general para todos los entes del Sec-

42 Artículo 13. Delimitación general.1. «Son contratos sujetos a una regulación armonizada los contratos de colaboración entre el sector público y el sector privado, en todo caso, y los contratos de obras, los de concesión de obras públicas, los de suministro, y los de servicios comprendidos en las categorías 1 a 16 del Anexo II, cuyo valor estimado, calculado conforme a las reglas que se establecen en el artículo 76 , sea igual o superior a las cuantías que se indican en los artículos siguientes, siempre que la entidad contratante tenga el carácter de poder adjudicador. Tendrán también la consideración de contratos sujetos a una regulación armonizada los contratos subvencionados por estas entidades a los que se refiere el artículo 17»".

43 Art. 20. Contratos privados.1. "Tendrán la consideración de contratos privados los celebrados por los entes, organismos y entidades del sector público que no reúnan la condición de Administraciones Públicas. Igualmente, son contratos privados los celebrados por una Administración Pública que tengan por objeto servicios comprendidos en la categoría 6 del Anexo Il, la creación e interpretación artística y literaria o espectáculos comprendidos en la categoría 26 del mismo Anexo, y la suscripción a revistas, publicaciones periódicas y bases de datos, así como cualesquiera otros contratos distintos de los contemplados en el apartado 1 del artículo anterior». 
tor Público, incluidos los contratos excluidos, a los que el Art. 4.2 declara de aplicación supletoria ${ }^{44}$.

\subsection{El ámbito subjetivo de la Ley 30/2007}

La pretensión de la LCSP de regular la contratación integral del sector público impone una clasificación o ámbito subjetivo de aplicación de la Ley particularmente compleja y farragoso, y obliga a establecer una calificación y clasificación propia de todos los entes del sector público creados, definidos y reconocidos en las leyes administrativas básicas y en la Ley General Presupuestaria45. A estos efectos, el artículo 3.1 enumera en sus letras a) a g) las entidades que han de sujetarse a la legislación de contratos públicos, si bien con muy distintos niveles de intensidad, según se trate de las Administraciones Públicas, Poderes Adjudicadores con forma mercantil, y del resto de las Empresas de titularidad pública; a pesar de las declaraciones de la Ley sobre la voluntad de aplicar la clasificación del sector público de la Ley General Presupuestaria, la realidad es que se establece una clasificación particular con un contenido y alcance muy distinto del resto de las grandes leyes administrativas. En este sentido, el Art. 3 -columna vertebral de la LCSP- en su núm. $1^{46}$ determina el concepto y clasifica los distintos tipos de entes que integran el sector público en orden descendiente,

44 El mayor o menor éxito de la reforma presentada, con un ambicioso artículo 1 que puede y debe desempeñar una importante función interpretativa, ha de depender de la corrección en el alcance efectivo de quién tiene consideración de poder adjudicador y debe aplicar los principios y reglas de esta LCSP. Es cierto que es ése uno de los objetivos principales del texto presentado, pero el resultado es, cuando menos, desolador. Nada se ha avanzado al introducir numerosas dudas interpretativas derivadas de la propia definición de los conceptos. En definitiva, más inseguridad jurídica en una ley de carácter estructurante para el ordenamiento jurídico-administrativo, lo que puede impedir la efectividad de los objetivos pretendidos con la reforma.

45 Así, el articulado de la Ley se ha estructurado en un Título preliminar dedicado a recoger unas disposiciones generales y cinco Libros que se dedican, sucesivamente, a regular la configuración general de la contratación del sector público y los elementos estructurales de los contratos, la preparación de estos contratos, la selección del contratista y la adjudicación de los contratos, los efectos, cumplimiento y extinción de los contratos administrativos, y la organización administrativa para la gestión de la contratación.

46 Artículo 3. Ámbito subjetivo.

1. A los efectos de esta Ley, se considera que forman parte del sector público los siguientes entes, organismos y entidades:

a) La Administración General del Estado, las Administraciones de las Comunidades Autónomas y las Entidades que integran la Administración Local.

b) Las entidades gestoras y los servicios comunes de la Seguridad Social.

c) Los organismos autónomos, las entidades públicas empresariales, las Universidades Públicas, las Agencias Estatales y cualesquiera entidades de derecho público con personalidad jurídica propia vinculadas a un sujeto que pertenezca al sector público o dependientes del mismo, incluyendo aquellas que, con independencia funcional o con una especial autonomía reconocida por la Ley, tengan atribuidas funciones de regulación o control de carácter externo sobre un determinado sector o actividad.

d) Las sociedades mercantiles en cuyo capital social la participación, directa o indirecta, de entidades de las mencionadas en las letras a a f del presente apartado sea superior al $50 \%$.

e) Los consorcios dotados de personalidad jurídica propia a los que se refieren el artículo 6.5 de la Ley 30/1992, de 26 de noviembre, de Régimen Jurídico de las Administraciones Públicas y del Procedimiento Administrativo Común, y la legislación de régimen local. 
comenzando por las Administraciones Públicas, sus Organismos Autónomos, y Empresas de titularidad pública -se requiere la titularidad de más del 50 por 100 del capital social-; más los denominados organismos reguladores independientes; los entes de la Seguridad Social, Universidades y Fundaciones de titularidad pública; y los Consorcios y Mutuas. La relación termina con el concepto de poder adjudicador: «Cualesquiera entes, organismos o entidades con personalidad jurídica propia, que hayan sido creados específicamente para satisfacer necesidades de interés general que no tengan carácter industrial o mercantil, siempre que uno o varios sujetos pertenecientes al sector público financien mayoritariamente su actividad, controlen su gestión, o nombren a más de la mitad de los miembros de su órgano de administración, dirección o vigilancia», que funciona como cláusula residual y reproduce literalmente la definición de organismo público de la Directiva 2004/18/CE, con la manifiesta finalidad de evitar nuevas controversias y litigios con la Comisión Europea ${ }^{47}$.

La Ley 30/2007 impone así su propia calificación formal de Administración Pública, con exclusión de su ámbito, Art.3.2 «in fine», de las entidades públicas empresariales: "No obstante, no tendrán la consideración de Administraciones Públicas las entidades públicas empresariales estatales y los organismos asimilados dependientes de las Comunidades Autónomas y Entidades locales.» Ello implica una evidente desconexión con el resto de la legislación básica del Estado: Ley de Funcionamiento del Tribunal de Cuentas, LOFAGE, LRJAPAC, y con la Ley de Patrimonio de las Administraciones Públicas, que conceden el tratamiento de Administración Pública a las entidades públicas empresariales, y sus equivalentes autonómicos y locales. En el mismo sentido, su DA Vigésimo quinta asimila el Museo del Prado, el Instituto Español de Comercio Exterior, la Sociedad Estatal de Participaciones Industriales, y Ente Público Puertos del Estado y Autoridades Portuarias, a las Entidades Públicas empresariales a los efectos de esta Ley, que pierden así su condición de Administración Pública, y sus poderes de dirección, interpretación y modificación de sus contratos, para transmutarse en poderes adjudicadores no administrativos, asimilados a los constituidos bajo forma mercantil ${ }^{48}$.

f) Las fundaciones que se constituyan con una aportación mayoritaria, directa o indirecta, de una o varias entidades integradas en el sector público, o cuyo patrimonio fundacional, con un carácter de permanencia, esté formado en más de un $50 \%$ por bienes o derechos aportados o cedidos por las referidas entidades.

g) Las Mutuas de Accidentes de Trabajo y Enfermedades Profesionales de la Seguridad Social.

h) Cualesquiera entes, organismos o entidades con personalidad jurídica propia, que hayan sido creados específicamente para satisfacer necesidades de interés general que no tengan carácter industrial o mercantil, siempre que uno o varios sujetos pertenecientes al sector público financien mayoritariamente su actividad, controlen su gestión, o nombren a más de la mitad de los miembros de su órgano de administración, dirección o vigilancia.

i) Las asociaciones constituidas por los entes, organismos y entidades mencionados en las letras anteriores.

47 Garlón Ruiz, M. (2004) «La Ley de Contratos de las Administraciones Públicas y su carácter estructurante del ordenamiento jurídico». Pp. 1801-1823 en Comentarios a La Ley de Contratos de las Administraciones Públicas, dirigido por Gómez-Ferrer Morant. Ed. Civitas.

48 Gimeno Feliu, J.M. ${ }^{a}$ (2008). «El nuevo ámbito subjetivo de aplicación de la Ley de Contratos del Sector Público: luces y sombras». RAP, Núm. 176 (CEPC): «EI Art. 4.1. n) de la Ley 30/2007: "Los negocios jurídicos en cuya virtud se encargue a una entidad que, conforme a lo señalado en el artículo 24.6, tenga atribuida 
A pesar del papel estrella que corresponde a la recepción del concepto de poder adjudicador ${ }^{49}$, la clasificación definitiva de la Ley sigue siendo la obligada distinción y separación entre las Administraciones Públicas en sentido estricto y el resto de los poderes adjudicadores, de naturaleza mercantil, art. 3.2. "Son Administraciones Públicas, las mencionadas en las letras a) y b) del apartado anterior, los Organismos autónomos, las Universidades Públicas, las entidades de derecho público que, con independencia funcional o con una especial autonomía reconocida por la Ley, tengan atribuidas funciones de regulación o control de carácter externo sobre un determinado sector o actividad, y las entidades de derecho público vinculadas a una o varias Administraciones Públicas o dependientes de las mismas que cumplan alguna de las características siguientes: que su actividad principal no consista en la producción en régimen de mercado de bienes y servicios destinados al consumo individual o colectivo, o que efectúen operaciones de redistribución de la renta y de la riqueza nacional, en todo caso sin ánimo de lucro, o que no se financien mayoritariamente con ingresos, cualquiera que sea su naturaleza, obtenidos como contrapartida a la entrega de bienes o a la prestación de servicios».

Esta distinción, obligada e imprescindible, a su vez delimita el ámbito subjetivo del contrato administrativo y requiere sine qua non la presencia de la Administración Pública, destinataria única de la nueva regulación de los contratos administrativos del Libro IV de la Ley, artículos 192 a 290, en cuanto sigue detentando los poderes de dirección, modificación e interpretación de unos contratos «administrativos» que ya sólo se distinguen del resto de los contratos del sector público (artículos 5 a 12, más el contrato subvencionado) por la presencia de una Administración, y por su directa vinculación al servicio público, según establece el art. 19 de la LCSP en redacción que se arrastra desde la reforma de 1973. Todo ello, sin perjuicio del mantenimiento del ámbito de los contratos privados de la Administración, y del aumento expreso de la lista de de los negocios excluidos del Art. 4. En definitiva, la LCSP sólo resulta de aplicación integral a la Administración pública entendida según su particular clasificación, que implica un ámbito subjetivo menor del contrato administrativo, y por ende una mayor posibilidad del recurso al arbitraje en entidades que, para otras leyes básicas, son Administración ${ }^{50}$.

la condición de medio propio y servicio técnico del mismo, la realización de una determinada prestación. No obstante, los contratos que deban celebrarse por las entidades que tengan la consideración de medio propio y servicio técnico para la realización de las prestaciones objeto del encargo quedarán sometidos a esta Ley, en los términos que sean procedentes de acuerdo con la naturaleza de la entidad que los celebre y el tipo y cuantía de los mismos, y, en todo caso, cuando se trate de contratos de obras, servicios o suministros cuyas cuantías superen los umbrales establecidos en la Sección II del Capítulo II de este Título Preliminar, las entidades de derecho privado deberán observar para su preparación y adjudicación las reglas establecidas en los artículos 121.1 y $174 "$ ".

49 Formulado por el Derecho comunitario para normalizar y sujetar a los principios de competencia, libre e igual acceso y no discriminación, a todos los entes que conforman la Administración Pública, en cuando que sus actividades no tienen naturaleza mercantil -no se sostienen en el mercado ni sus órganos de gestión y administración se nombran por los accionistas, ni desde luego se constituyen pensando en una independencia real y efectiva de la Administración, sometiéndose a las reglas del mercado.

50 Art. 39 Arbitraje. "Los entes, organismos y entidades del sector público que no tengan el carácter de Administraciones Públicas podrán remitir a un arbitraje, conforme a las disposiciones de la Ley 60/2003, de 
Entre otras consecuencias, la forma mercantil -incluidas las empresas públicas y los puertos del Estado- determina la calificación de todos los contratos de éstos entes como privados; por lo que corresponderá a la jurisdicción civil (Art. 21.2 de la LCSP) el conocimiento de los actos de preparación, selección o licitación, adjudicación, ejecución y liquidación (salvo que se trate de contratos sujetos a regulación armonizada, que corresponden a la jurisdicción contencioso-administrativa hasta la adjudicación de la contratación) ${ }^{51}$. En consecuencia, la calificación de una entidad o ente público como Administración Pública resulta absolutamente decisiva en orden al alcance de la aplicación de la Ley ${ }^{52}$. Por otro lado, obliga al Legislador a establecer una serie de matizaciones y excepciones en los artículos 92, 121, y 174 de la LCSP53, para minorar el rigor exigible a las Administraciones en materia de garantías y en materia de preparación de los contratos a celebrar por los poderes adjudicadores con forma mercantil; $\mathrm{y}$, en los procedimientos de adjudicación, para liberar en el Art. 175 a estos poderes adjudicadores con forma de sociedad privada de los requisitos de publicación y documentación establecidos en los artículos 134, 136, 140, 144, que sólo serán de aplicación a la Administración Pública. Por supuesto, los contratos de estos poderes adjudicadores «mercantiles» son siempre de naturaleza privada y su conocimiento corresponde a la Jurisdicción ordinaria, salvo los actos de preparación y adjudicación de los contratos sujetos a regulación armonizada, para la preparación y adjudicación del resto de sus contratos deberán aprobar el régimen de instrucciones internas que se regulan en los artículos 175 y 176 de la Ley54.

La LCSP se separa del criterio establecido por la Ley 33/2003, de 3 de noviembre, de Patrimonio de las Entidades Públicas, que mantiene a las Empresas Públicas, a los Puertos del Estado y a los entes asimilados a las mismas en el sector de las Administraciones Públicas, declarando expresamente que todas las fases previas del denominado "expediente patrimonial» constituyen actos administrativos «separables», cuyo conocimiento corresponde a la jurisdicción contencioso-administrativa55. Se consoli-

23 de diciembre, de Arbitraje, la solución de las diferencias que puedan surgir sobre los efectos, cumplimiento y extinción de los contratos que celebren».

51 T. Font i Llovet, T. (2003) «Control jurisdiccional de la selección de contratistas», en libro colectivo Estudios de Derecho Público Económico. Libro Homenaje al profesor S. Martin Retortillo, ed. Civitas. Pp. 1453-1454. Moreno Molina (1996) «Contratos públicos: Derecho comunitario y Derecho español», ed. MacGraw-Hill, p. 315. Rivero Ysern, (1988) «¿Actos separables en los contratos de los entes públicos sometidos a derecho privado?», p. 701, en Homenaje a Clavero Arévalo. Ed. Civitas.

52 Salvo que por razón del umbral se trate de contratos típicos sujetos a regulación armonizada, según los arts. 14 a 16 de la Ley 30/2007, y sólo en la fase de preparación y adjudicación.

53 La capacidad y la solvencia del empresario resultan de aplicación general, salvo las contadas referencias expresas a la Administración Pública: necesidad de clasificación y revisión de precios, entre otros aspectos.

54 Macera, B. (2001) «La sujeción a control contencioso-administrativo del fieri de los contratos celebrados por ciertas sociedades mercantiles públicas: Un remedio improcedente a una tendencia privatizadora ilegítima», RAP, núm. 155, pp. 242-251. Borrajo Iniesta (1993) «El intento de huir del Derecho Administrativo», REDA, núm. 78, pp. 234 y ss.

55 Artículo 110. «Régimen jurídico de los negocios patrimoniales.

1. Los contratos, convenios y demás negocios jurídicos sobre bienes y derechos patrimoniales se regirán, en cuanto a su preparación y adjudicación, por esta Ley y sus disposiciones de desarrollo y, en lo no previs- 
da un tratamiento contrario y una asimetría en su regulación en la LCSP y en la Ley de Patrimonio de las Administraciones Públicas ${ }^{56}$, cuando la LCSP es de aplicación supletoria a la contratación patrimonial por disposición expresa del Art. 4.2-57; y por la remisión cruzada a favor de las normas de contratación pública que se declaran de aplicación supletoria en el artículo 110.1 de la Ley 33/2003, que unido a la falta de adecuación de la Ley de Patrimonio a la nueva terminología -no se ha aprovechado la LCSP para establecer la necesaria adecuación de la Ley de Patrimonio, que sigue hablando de subasta y concurso- complica la efectividad de la preferente aplicación de los principios de la Ley 30/2007. En todo caso, esta diferencia de trato no tiene justificación en la LCSP, salvo que se pretenda favorecer el recurso al arbitraje y limitar en lo posible el ámbito de la jurisdicción contencioso-administrativa; al mismo tiempo que nos advierte sobre la conveniencia de conceder un tratamiento homogéneo a la contratación de todos los poderes adjudicadores, medios propios y empresas con derechos especiales, -son Administración Pública con forma privada-, que debe extenderse a los sectores regulados por la Ley 31/2007, para distinguir nítidamente los entes que son funcionalmente Administración y deben regirse por las normas del Derecho administrativo ${ }^{58}$, del resto de las empresas financieras o manufactureras del sector público que deben someterse plenamente al libre mercado.

\subsection{La estructura concéntrica de la Ley 30/2007}

A pesar de las nuevas prioridades de la LCSP, no se prescinde por completo de una parte general, que puede identificarse en la mera existencia de un Título Preliminar, artículos 1 a 21, destinado a la definición de los objetivos y finalidades de la Ley, establecer su peculiar ámbito subjetivo, definir con carácter general los tipos contractuales, los contratos sujetos a regulación armonizada, y los contratos públicos y privados del sector público sujetos a la regulación de la Ley. Y en no menor medida, en

to en estas normas, por la legislación de contratos de las Administraciones públicas. Sus efectos y extinción se regirán por esta Ley y las normas de derecho privado.

2. En las entidades públicas empresariales y en los organismos públicos Puertos del Estado y Autoridades Portuarias, la preparación y adjudicación de estos negocios, así como la competencia para adoptar los correspondientes actos, se regirán, en primer término, por lo establecido en sus normas de creación o en sus estatutos, con aplicación, en todo caso, de las previsiones recogidas en el artículo 147 de esta Ley.

3. El orden jurisdiccional civil será el competente para resolver las controversias que surjan sobre estos contratos entre las partes. No obstante, se considerarán actos jurídicos separables los que se dicten en relación con su preparación y adjudicación y, en consecuencia, podrán ser impugnados ante el orden jurisdiccional contencioso-administrativo de acuerdo con su normativa reguladora.»

56 En la Ley 33/2003, de Patrimonio de las AAPP, el conocimiento de las reclamaciones interpuestas contra el denominado expediente patrimonial -se trate de Administraciones o de Entes asimilados, Empresas Públicas y Puertos del Estado, art. 166.1-, corresponde siempre a la jurisdicción contencioso administrativa.

57 2. Los contratos, negocios y relaciones jurídicas enumerados en el apartado anterior se regularán por sus normas especiales, aplicándose los principios de esta Ley para resolver las dudas y lagunas que pudieran presentarse.

58 Se terminaría así en parte la confusión sobre el problema de la forma en los modos de gestión de los servicios públicos prestados por gestión directa. Arts. 85 y 86 de la Ley $7 / 85$, de Bases del Régimen Local. 
los contenidos del Título I del Libro I. «Disposiciones generales sobre contratos del sector público», artículos 22 a 39, que se refieren a la racionalidad de la contratación, plazos, remisión estadística de datos, supuestos de invalidez y nulidad, jurisdicción competente, régimen de libertad de pactos, requisitos formales y régimen de invalidez de los contratos administrativos y privados; más lo dispuesto para el recurso administrativo especial en materia de contratos armonizados, medidas provisionales y recurso al arbitraje de todos los entes del sector público con forma mercantil o privada. También pueden entenderse incluidos en esta parte general teórica de la Ley, los inmediatos artículos 40 a 42, capítulo I del Título II de la Ley, destinados a regular la competencia para contratar, y establecer la trascendental novedad del perfil del contratante y la figura del responsable del contrato. Si bien esta parte preliminar se refiere ahora al ámbito general de la contratación pública y no al restringido ámbito de los contratos administrativos, para los que se reserva el Título I del Libro IV. «Efectos, Cumplimiento y Extinción de los Contratos Administrativos», artículos 192 a 211 de la Ley que, por razones de sistemática, se sitúa de forma clara y manifiesta inmediatamente después de la regulación armonizada, para reseñar que nos encontramos fuera del ámbito de las obligaciones de la Directiva 18/2004/CE. En consecuencia, la verdadera parte general de la LCSP, que determina por completo su estructura, es la recepción de los procedimientos de contratación de la Directiva 18/2004/CE, que se regulan en los Libros II «Preparación de los contratos» y III, "Selección del contratista y adjudicación de los contratos», artículos 92 a 191, que junto con los artículos 43 a 91, (capacidad y solvencia del empresario; objeto, precio y cuantía del contrato; y garantías exigibles en la contratación) constituyen el núcleo de la incorporación de la Directiva, y el nicho normativo al que se refiere la Exposición de Motivos de la Ley, con pretensión de aplicación general a todo el sector público, con independencia de la naturaleza pública o privada de la contratación.

No obstante, la necesaria comprensión de la nueva estructura de la LCSP, y del distinto alcance de cada parte, sólo se obtiene cuando se relaciona la clasificación tripartita del sector público que establece su Art. 3 (Administraciones Públicas, Poderes Adjudicadores, y resto de Empresas de titularidad pública), con las reglas especiales establecidas para la adjudicación de otros contratos del sector público en el Capítulo II del Libro III de la Ley, artículos 173 a 177, que distinguen entre Administración Pública y poderes adjudicadores con forma societaria, para relajar el cúmulo de requisito procedimentales que se requiere a la Administración Pública, cuando se trate de otros poderes adjudicadores -Empresas Públicas, Puertos del Estado y todos los entes con forma mercantil creados para satisfacer una necesidad de interés general no mercantil-59; y para excluir la aplicación de los procedimientos normalizados al resto de las empresas del sector público, y a los propios poderes adjudicadores, cuando,

59 Artículo 173. Delimitación general. Los poderes adjudicadores que no tengan el carácter de Administraciones Públicas aplicarán, para la adjudicación de sus contratos, las normas de la presente sección.

Artículo 174. Adjudicación de los contratos sujetos a regulación armonizada.

1. La adjudicación de los contratos sujetos a regulación armonizada se regirá por las normas establecidas en el Capítulo anterior con las siguientes adaptaciones: 
por razón de la cuantía, no se alcancen los umbrales de la contratación armonizada. Se entiende entonces los distingos entre poderes adjudicadores no administrativos y la Administración Pública, y la exclusión de las entidades públicas empresariales del ámbito de la Administración Pública. Puesto que estos poderes adjudicadores con forma de sociedad mercantil sólo están sujetos a la LCSP en materia de contratación normalizada; para el resto de sus contratos y para el resto de las sociedades del sector público de naturaleza y actividad mercantil, la Ley se remite a la aprobación de unas instrucciones internas, que hagan efectivos los principios de Derecho comunitario, que se aprueben por cada entidad o sociedad, pero que sólo en el ámbito estatal se establece la garantía del previo informe de la Abogacía del Estado ${ }^{60}$.

La Ley 30/2007, de Contratos del Sector Público establece así un ámbito de aplicación, que se ha representado de forma gráfica con tres círculos concéntricos, que se corresponden con muy distintos niveles de aplicación ${ }^{61}$. El primero corresponde a las Administraciones Públicas, que están obligadas a la aplicación integral de la LCSP en los contratos administrativos, a su aplicación a los actos separables cuando se trate de contratos civiles de la Administración, y a su aplicación supletoria en los negocios excluidos por el Art. 4.1. El segundo escalón o nivel corresponde a los poderes adjudicadores constituidas bajo fórmulas de Derecho privado, que sólo son funcionalmente Administración Pública, por lo que exclusivamente les son de aplicación las disposiciones de los Libros II y III sobre contratación armonizada, con las excepciones que figuran en el artículo 174, y con las que establecen en los preceptos referidos exclusivamente a la Administración Pública; sin perjuicio de resultarles de aplicación los principios generales del Título preliminar, y todo lo dispuesto en materia de capacidades, importes y garantías, en cuanto se trate de contratos sujetos a regulación armonizada. Cuando se trate de los contratos de los poderes adjudicadores de cuantía inferior a la contratación armonizada, y de las empresas del sector público empresarial, los artículos 175 y 176 de la Ley establecen un tercer escalón, en el que la Ley no se aplica directamente, sino que se remite a las instrucciones de orden interno ${ }^{62}$, que

60 Aspecto positivo de la LCSP, que va más allá de lo que previene la Directiva 2004/18, de 31 de marzo, de contratos públicos (y conforme a lo previsto en la Comunicación interpretativa de la Comisión ya citada de 1 de agosto de 2006), obligando a los mismos a que apliquen unas reglas de transparencia y concurrencia que permitan adjudicar a la oferta económicamente más ventajosa. Esta previsión introduce un régimen más detallado que la previsión de la Disposición Adicional Sexta de la LCAP, en un intento de garantizar objetividad y eficiencia de fondos públicos.

61 Sosa Wagner, F. (2008) «La Ley de Contratos del Sector Público y el murciélago». Actualidad Jurídica Aranzadi, núm. 743: «Describe el legislador el ámbito subjetivo, agrupando en tres círculos concéntricos las personificaciones jurídicas afectadas. El círculo más pequeño, el núcleo esencial, es la enumeración «a los efectos de la Ley» de las Administraciones públicas; engloba este primer círculo y añade nuevos organismos el segundo, que se refiere a «los poderes adjudicadores», para, en último lugar, relacionar todas las Administraciones, instituciones, sociedades y entes que integran el sector público. La descripción resulta aparentemente muy elemental; sin embargo, su exégesis no está exenta de dudas. Es más, al tratar el legislador de mantenerla en todo su discurso, ha introducido un pie forzado que resquebraja tradicionales conquistas del régimen de protección del interés público».

62 INSTRUCCIÓN N ํ1/2008 (MJ) Abogacía General del Estado sobre Contratación de las Fundaciones del Sector Público Estatal, Sociedades Mercantiles del Estado y Entidades Públicas Empresariales dependientes de la Administración del Estado da cumplimiento a la exigencia legal. Circular Informativa 
a pesar de la distinta naturaleza de poderes adjudicadores y empresas mercantiles, se configuran de forma casi idéntica como reglas de orden interno que deben publicarse en todo caso en el perfil del contratante ${ }^{63}$. En el caso de sociedades mercantiles del patrimonio empresarial del Estado, de las CCAA o de los Entes Locales ${ }^{64}$, le corresponde a sus instrucciones internas detallar los requisitos de la publicación ${ }^{65}$.

\subsection{Naturaleza y alcance de las Instrucciones de Contratación de la Ley 30/2007}

Las instrucciones de contratación reguladas en los artículos 175 y 176 de la LCSP, para las empresas de titularidad pública, según tengan o no la consideración de poder adjudicador, constituyen una de las grandes novedades de la LCSP, y el instrumento jurídico diseñado por el Legislador para regular los procedimientos de contratación del sector público empresarial y de los poderes adjudicadores «mercantiles» cuando contraten por debajo de las cuantías sometidas a armonización por la Unión Europea. La Ley no declara expresamente su naturaleza jurídica; sin embargo, es evidente que no se establece un tratamiento normativo, opción que se pudo adoptar sin mayores obstáculos remitiendo la competencia para su aprobación -las empresas, por muy públicas que sean, no pueden aprobar normas jurídicas- a las Administraciones Públicas de las que indefectiblemente dependen. Esta medida obligaba a establecer procedimientos y órganos de control administrativos sobre las empresas dependientes en materia de contratación; puesto que sería inevitable establecer una vía de recurso administrativo -directo o indirecto, con ocasión de recurrir la adjudicación- contra las mismas normas y contra los acuerdos adoptados bajo su amparo, con el paradójico efecto de entregar el conocimiento de los recursos y pleitos que se pudieran interponerse contra las adjudicaciones de unos contratos privados, celebrados por empresas privadas, a la jurisdicción contencioso-administrativa siempre que el recurso o la demanda se fundamentase en la ilegalidad de tales normas o en la indebida aplicación de las mismas; so pena de encomendar el conocimiento de la legalidad de las

1/2008, de 3 de marzo, de la Junta Consultiva de Contratación Administrativa de Aragón parece seguir el camino abierto por la Abogacía del Estado.

63 El Art. 121.2 LCSP, en contratos distintos a los mencionados en el apartado anterior de cuantía superior a 50.000 euros, los poderes adjudicadores que no tengan el carácter de Administraciones Públicas, obliga a elaborar un pliego, en el que se establezcan las características básicas del contrato, el régimen de admisión de variantes, las modalidades de recepción de las ofertas, los criterios de adjudicación y las garantías que deberán constituir, en su caso, los licitadores o el adjudicatario, siendo de aplicación, asimismo, lo dispuesto en el artículo 104. Estos pliegos serán parte integrante del contrato.

64 Art. 166 de la Ley 33/2003, de 3 de noviembre, de patrimonio de las Administraciones Públicas, cuyas definiciones y contenidos se han «copiado» por la práctica totalidad de las CCAA, entre otras, por el DL 2/2007, de patrimonio del País Vasco; y, por la ley 3/2003, de Patrimonio de Cantabria.

65 En definitiva, la Ley 30/2007, establece un concepto formal de poder adjudicador, que está en función de la obligada aplicación de los procedimientos de coordinación de la adjudicación de los contratos públicos de la Directiva 18/2004/CE, con la decidida intención de evitar una nueva condena por incumplimiento de la trasposición de la nueva Directiva; por debajo del umbral cuantitativo de la armonización, la Ley 30/2007 pierde este tratamiento especial y se asimila al resto del mundo empresarial público, se trate de empresas de servicios público con derechos especiales o exclusivos, medios propios, y empresas de mercado o manufactureras. 
normas administrativas y la regularidad de su aplicación a la jurisdicción ordinaria. Y por lo tanto, volver al procedimiento administrativo del que se pretendía salir, con la constitución de este tipo de sociedades destinadas en más de un caso a la gestión de servicios públicos de forma directa.

No es este el criterio seguido por la LCSP, que está presidida por el criterio formal de la máxima separación posible entre Administración Pública y el resto de los entes del sector público, privatizando incluso buena parte de los entes administrativos. Sólo la Administración Pública puede aprobar normas y suscribir actos administrativos y, por ende, los contratos administrativos en el ámbito de sus competencias (obras, servicios, suministros, gestión de servicios públicos y contratos de colaboración público-privada, y los especiales por su directa vinculación con el giro o tráfico de la Administración contratante o por satisfacer directamente una necesidad pública), al igual que es administrativa la fase preparatoria de sus contratos privados, que también se manifiesta en actos administrativos que pueden separarse del contrato mismo y entregarse, por ende, junto con el conocimiento de los contratos típicos, estén o no sujetos a regulación armonizada, a la jurisdicción contencioso administrativa ${ }^{66}$.Los negocios y contratos excluidos, como la contratación patrimonial y los negocios financieros, se rigen por su legislación específica en todos los aspectos y fases. Por el contrario, todos los entes dependientes de la Administración con forma privada -incluso las Empresas Públicas y los Puertos del Estado- suscriben contratos privados, por lo que el conocimiento de todo lo relacionado con su contratación corresponde a la jurisdicción ordinaria en todo caso. La LCSP sólo admite una modulación obligada por el Derecho comunitario ${ }^{67}$. Por ende, la remisión a unas instrucciones de contratación no podía conllevar en ningún caso la intervención de la jurisdicción contencioso-administrativa.

Se explica así la solución dada por los artículos 175 y 176 de la Ley 30/2007 al configurar, para todos los entes del sector público creados al amparo del Derecho Privado sin distinción -salvo para la contratación armonizada de los que tengan naturaleza de poderes adjudicadores: entidades públicas empresariales y todas las creadas para satisfacer necesidades interés general no mercantil ${ }^{68}-$, unas instrucciones de contratación, que se regulan por separado para los poderes adjudicadores y para el resto de

66 Artículo 21. Jurisdicción competente. 1. «El orden jurisdiccional contencioso-administrativo será el competente para resolver las cuestiones litigiosas relativas a la preparación, adjudicación, efectos, cumplimiento y extinción de los contratos administrativos. Igualmente corresponderá a este orden jurisdiccional el conocimiento de las cuestiones que se susciten en relación con la preparación y adjudicación de los contratos privados de las Administraciones Públicas y de los contratos sujetos a regulación armonizada, incluidos los contratos subvencionados a que se refiere el artículo 17»".

67 DIRECTIVA 89/665/CEE DEL CONSEJO, de 21 de diciembre de 1989, relativa a la coordinación de las disposiciones legales, reglamentarias y administrativas referentes a la aplicación de los procedimientos de recurso en materia de adjudicación de los contratos públicos de suministros y de obras, no incorporada en debida forma al Derecho interno por el art. 37 de la LCSP, lo que impone la existencia de un acto administrativo que arrastra la competencia a favor de la jurisdicción contencioso administrativa.

68 El criterio funcional de sometimiento a una regulación armonizada de los poderes adjudicadores mercantiles no determina la sujeción de la entidad a la jurisdicción contencioso-administrativa-, conforme a su verdadera naturaleza; por el contrario, prevalece el criterio de la forma privada. 
los entes del sector público, aunque tienen la misma naturaleza y similar y contenido: se trata de unos acuerdos de orden interno que, a modo de condiciones generales de contratación, aprobadas por el órgano competente de gobierno de la sociedad, sin relación de dependencia o subordinación alguna con la Administración de tutela y control de la sociedad o entidad y sin que en ningún caso se pueda considerar que se trata de normas administrativas, aunque es obligatorio publicarlas en el perfil del contratista de cada entidad y ponerlas a disposición de los interesados, rigen efectivamente la contratación de estas entidades y empresas.

Como opina una buena parte de la doctrina ${ }^{69}$, si se trataba de regular la contratación del sector público, con independencia de autorizar una remisión normativa más o menos amplia, al menos para los poderes adjudicadores, se debió establecer una regulación simplificada que garantizase en todo caso y por todas las Administraciones la elaboración de unas instrucciones con la densidad suficiente para posibilitar una aplicación práctica y sencilla de los principios que rigen la contratación armonizada; aplicar sin excepciones el régimen de la LCSP en materia de incapacidades, prohibiciones, cuantías, penalidades a todas las sociedades y entes del sector público sin distinción; y declarar de aplicación supletoria de los procedimientos abiertos, restringidos en todo caso y para todos los entes y empresas del sector público, sin perjuicio de la sujeción de los poderes adjudicadores a la contratación armonizada, y de las necesarias excepciones para las empresas de mercado.

Alternativamente, se pudo reservar el régimen de instrucciones internas, exclusivamente, para el sector empresarial. Sistemática que posibilita la unidad de fuero de toda la fase previa de la contratación de los poderes adjudicadores, con independencia de la cuantía necesaria para quedar sometido a las reglas de los contratos armonizados, y es plenamente coherente con la verdadera naturaleza de los entes del sector público con forma mercantil, que no tienen naturaleza empresarial, y deben remitir el conocimiento de sus controversias en materia de preparación, selección, y adjudicación de sus contratos a la jurisdicción contencioso-administrativa. La opción por una deslegalización deja todo a la voluntad política de las Comunidades Autónomas y de los Entes Locales, en sus respectivos ámbitos, con el consiguiente riesgo de dispersión y fragmentación de la contratación del sector público.

Aunque la Ley no es tan innovadora como se mantiene por sus promotores. Existen antecedentes de instrucciones de contratación en la contratación patrimonial de las empresas estatales en el art. 178 de la Ley 33/2003; y en la regulación de la concertación de operaciones de crédito de las Corporaciones Locales, a través de las Bases de Ejecución del Presupuesto, previstas en el artículo 52 del TR de la Ley 39/88, reguladora de las Haciendas Locales, aprobado por DL 2/2004, de 5 marzo $^{70}$, excluidas del

69 Gimeno Feliu, J.M. ${ }^{\text {a }}$ Op. cit. Núm. 48.

70 Al día de la fecha, sigue pendiente de adaptación a la Ley 30/2007, y sigue refiriéndose a los artículos 3 y 9 del TR 2/2000, de la Ley 13/95, de Contratos de las Administraciones Públicas, vigente desde 10 de marzo de 2003. 
ámbito del TR 2/2000, y ahora de la LCSP, art. 4.1 I)71. Aún cuando la remisión legislativa se establece sin un previo encuadramiento mínimo que hubiera facilitado la aprobación y el enjuiciamiento de unas instrucciones homogéneas por las distintas Administraciones $^{72}$, hay que reconocer que el nuevo régimen de instrucciones internas supone una mejora manifiesta sobre el sistema de la DA 6. a de la Ley 13/95, y también sobre las exigencias de las la Directiva 2004/18, de 31 de marzo, de contratos públicos, que sólo alcanza a los contratos normalizados de los poderes adjudicadores, obligando la LCSP a la aprobación de unas reglas de transparencia y concurrencia que permitan adjudicar a la oferta económicamente más ventajosa a todos los entes del Sector Público.

En todo caso, es necesario denunciar que por el juego combinado de las exclusiones dispuestas para la contratación patrimonial en el art. 4.1 p) de la Ley 30/2007, con alcance general para todas las Administraciones Públicas; en relación con las reguladas para las sociedades estatales de mercado en el artículo 166.2 de la Ley 33/2003; para las sociedades mercantiles de las CCAA en sus respectivas Leyes de Patrimonio; y para las sociedades municipales en la Ley $57 / 2003^{73}$, toda la contratación patrimonial de las empresas de mercado de todas las Administraciones Públicas queda remitida por entero al Derecho privado, con la sola excepción de la aplicación de las reglas contables, fiscales y presupuestarias que proceden por su mera pertenencia al sector público, y salvo las exigencias de control que dimanan de la aplicación de la Directiva 111/2006/CE sobre Transparencia ${ }^{74}$; sin perjuicio de resultar de aplicación los principios de la LCSP, en virtud de lo dispuesto en su art. 4.2, y de la

71 Los contratos relativos a servicios financieros relacionados con la emisión, compra, venta y transferencia de valores o de otros instrumentos financieros, en particular las operaciones relativas a la gestión financiera del Estado, así como las operaciones destinadas a la obtención de fondos o capital por los entes, organismos y entidades del sector público, así como los servicios prestados por el Banco de España y las operaciones de tesorería.

72 Artículo 176. Régimen de adjudicación de contratos.1 « Los entes, organismos y entidades del sector público que no tengan la consideración de poderes adjudicadores deberán ajustarse, en la adjudicación de los contratos, a los principios de publicidad, concurrencia, transparencia, confidencialidad, igualdad y no discriminación.2. La adjudicación de los contratos deberá efectuarse de forma que recaiga en la oferta económicamente más ventajosa.3. En las instrucciones internas en materia de contratación que se aprueben por estas entidades se dispondrá lo necesario para asegurar la efectividad de los principios enunciados en el apartado 1 de este artículo y la directriz establecida en el apartado 2. Estas instrucciones deben ponerse a disposición de todos los interesados en participar en los procedimientos de adjudicación de contratos regulados por ellas, y publicarse en el perfil de contratante de la entidad. En el ámbito del sector público estatal, estas instrucciones deberán ser informadas antes de su aprobación por el órgano al que corresponda el asesoramiento jurídico de la correspondiente entidad.».

73 Regulación que, a pesar de no tener carácter básico en la Ley 33/2003, se ha copiado en las nuevas Leyes de Patrimonio de las Comunidades Autónomas que, como la 3/2006, de Cantabria, destinan también un título completo a la regulación del patrimonio empresarial, con una reglamentación que reproduce casi por entero la regulación estatal.

74 Orden EHA/614/2009, de 3 de marzo, por la que se regula el contenido del informe al que hace mención el artículo 129.3 de la Ley 47/2003, de 26 de noviembre, General Presupuestaria.

La Ley 47/2003, de 26 de noviembre, General Presupuestaria, establece en su artículo $129 \cdot 3$ que las sociedades mercantiles estatales, las entidades públicas empresariales, el resto de entes del sector público estatal sometidos a los principios y normas de contabilidad recogidos en el Plan General de Contabilidad de la empresa española y las fundaciones del sector público estatal presentarán, junto con sus cuentas anuales, un informe relativo al cumplimiento de las obligaciones de carácter económico-financiero que asumen dichas entidades como consecuencia de su pertenencia al sector público. 
posibilidad de establecer o aprobar unas instrucciones para este tipo de entidades en el ámbito de la Administración del Estado, cuyo contenido y ámbito está indeterminado en la Ley ${ }^{75}$. La contratación patrimonial de las sociedades de titularidad pública queda sin regulación, cuando nada impedía extender a este tipo de contratos, a pesar de tratarse de una materia excluida, el mismo régimen de instrucciones a publicar en el perfil del contratante. Se hubiera evitado así el oscurantismo de la contratación patrimonial de este tipo de sociedades que gestionan una parte importante de los patrimonios públicos sin regulación y sin controles específicos con resultados escandalosos, al menos en la Administración Local ${ }^{76}$.

\section{CONSIDERACIONES FINALES}

\subsection{Necesidad de establecer una regulación homogénea de los poderes adjudicadores}

El Legislador español incorpora un concepto formal de poder adjudicador en la LCSP, que no da cumplimiento a la obligación de identificación que se establece en el artículo 9 de la Directiva 18/2004/CE77. Contrasta con el listado que figura en la DA

Asimismo esta modificación viene motivada por la necesaria adaptación a la Ley 30/2007, de 30 de octubre, de Contratos del Sector Público, por la que queda derogado el Texto Refundido de la Ley de Contratos de las Administraciones Públicas, aprobado por el Real Decreto Legislativo 2/2000, de 16 de junio.

Artículo 1. Ámbito de aplicación. Esta norma es de aplicación a las siguientes entidades: a) Entidades públicas empresariales. b) Sociedades mercantiles estatales. c) Fundaciones del sector público estatal. d) Resto de entes del sector público estatal sometidos a los principios y normas de contabilidad recogidos en el Plan General de Contabilidad de la empresa española.

c) Información relativa al cumplimiento de la Ley 30/2007, de 30 de octubre, de Contratos del Sector Público y otra normativa en materia de procedimientos de contratación.

75 Artículo 178 de la Ley 33/2003. Instrucciones. 1. En casos excepcionales, debidamente justificados, el Ministro al que corresponda su tutela podrá dar instrucciones a las sociedades previstas en el artículo 166.2, para que realicen determinadas actividades, cuando resulte de interés público su ejecución.

2. Cuando las instrucciones que imparta el ministerio de tutela impliquen una variación de los Presupuestos de Explotación y Capital de acuerdo con lo dispuesto en el Real Decreto Legislativo 1091/1988, de 23 de septiembre, por el que se aprueba el texto refundido de la Ley General Presupuestaria, el órgano de administración no podrá iniciar la cumplimentación de la instrucción sin contar con la autorización del órgano competente para efectuar la modificación correspondiente.

76 Entre otras, todas las personificaciones de servicios públicos locales en forma mercantil que se regulan en el artículo 85.1 de la ley 7/85, de 2 de abril, de Bases del Régimen Local.

77 Son considerados Apoderes adjudicadores: el Estado, los entes territoriales, los organismos de Derecho público y las asociaciones constituidas por uno o más de dichos entes o de dichos organismos de Derecho público.

Es considerado organismo de Derecho público cualquier organismo:

a) creado específicamente para satisfacer necesidades de interés general que no tengan carácter industrial o mercantil,

b) dotado de personalidad jurídica y

c) cuya actividad esté mayoritariamente financiada por el Estado, los entes territoriales u otros organismos de Derecho público, o bien cuya gestión se halle sometida a un control por parte de estos últimos, o bien cuyo órgano de administración, de dirección o de vigilancia esté compuesto por miembros de los cuales más de la mitad sean nombrados por el Estado, los entes territoriales u otros organismos de Derecho público. 
Segunda de la Ley 31/2007, sobre Procedimientos de Contratación en los Sectores del Agua, la Energía, los Transportes, y los Servicios Postales, que en tramitación y aprobación casi conjunta, incorpora la Directiva 17/2004/CE78 y los conceptos de Medio Propio, Poder Adjudicador y Empresa con derechos especiales y exclusivos, con un anexo completo que facilita su aplicación ${ }^{79}$; sin que la obligación de identificar a todos los medios propios que figura en el art. 24.6 de la LCSP sea suficiente.

Se establece así un concepto de poder adjudicador de las sociedades públicas de gestión, que implica un tratamiento dual de la contratación de estas entidades que son funcionalmente Administración Pública. De esta manera, sólo se someten por entero a la Directiva y a la Ley los contratos propios de éstas sociedades sujetos a regulación armonizada. Para el resto de sus contratos, la LCSP se remite a unas instrucciones internas, que no garantizan adecuadamente la aplicación de los principios de publicidad, transparencia e igualdad de acceso. Lo que a la postre dificulta su necesario control público, y en cierto sentido santifica, normaliza y favorece la huida del Derecho público hacia formas de gestión privadas, que terminan por entregar, en la mayoría de las Comunidades Autónomas, todas las iniciativas nuevas en manos de sociedades creadas «ad hoc», sin estudio previo, dotación presupuestaria, o calificación alguna, cuando resulta que se trata, en la mayoría de los casos, de mera gestión administrativa, que por esta vía queda libre de procesos de selección de personal, informes de intervención, y procedimientos de contratación, como puede constatarse con un examen de los Presupuestos consolidados de los CCAA de los últimos ejercicios ${ }^{80}$. Sin que por otra parte se identifique y justifique adecuadamente la finalidad de tales organismos y sociedades ni su condición de "poder adjudicador» o «medio propio», o mera sociedad de mercado, cuando resulta obligado por aplicación directa de las Directivas 18/2004/CEE, y 111/2006/CE de Contratación y de Transparencia, respectivamente, y cuando con in-

En el anexo III figuran las listas no exhaustivas de los organismos y de las categorías de organismos de Derecho público que cumplen los criterios enumerados en las letras a), b) y c) del párrafo segundo. Los Estados miembros notificarán periódicamente a la Comisión las modificaciones que se hayan producido en sus listas.

78 Art. 3.1 Entidades contratantes: «Quedarán sujetas a la presente Ley, siempre que realicen alguna de las actividades enumeradas en los artículos 7 a 12, las entidades contratantes que sean organismos de derecho público o empresas públicas y las entidades contratantes que sin ser organismos de derecho público o empresas públicas, tengan derechos especiales o exclusivos según se establece en el artículo 4».

79 Ley 4/2007. Artículo 14. Definición de empresas públicas manufactureras 1.- Se entenderá por empresas públicas que realizan su actividad principal en el sector manufacturero, a los efectos de esta Ley, aquellas empresas cuya actividad ordinaria, entendida ésta como aquella actividad que es desarrollada por la empresa regularmente y por la que obtiene ingresos de carácter periódico que representan al menos el 50 por ciento del importe neto de su cifra de negocios, sea la transformación mecánica, física o química de materiales, sustancias o componentes en nuevos productos.

2. En particular, se considerará que cumplen esta definición las empresas que realicen cualquiera de las actividades que se especifican en el anexo que acompaña a la presente Ley.

80 Tolibar Alas, L (2008) «EL Personal Local y el Nuevo Marco Regulador de la Función Pública» REALA. Núm. 308 septiembre-diciembre, p. 33: «... Justamente por ello, la Disposición Adicional Primera EBEP declarará que, al menos, los principios contenidos en los artículos 52, 53, 54, 55 y 59 (deberes de conducta, éticos, principios rectores de acceso y reserva de cupo a favor de personas con discapacidad) serán de aplicación, también, a las entidades del sector público, incluido expresamente el local, que no tengan el carácter de Administración Pública». 
dependencia de la forma elegida para su constitución y configuración, dependen de una Administración que controla de su gestión, dirección y financiación, por lo que desde cualquier consideración son Administración; de tal manera que lo adecuado era y seguirá siendo generalizar el sistema de recurso administrativo ante el órgano de tutela y entregar el conocimiento de los acuerdos de preparación y adjudicación a la jurisdicción contencioso-administativa en todo caso.

\subsection{Superación y abandono de la doctrina del contrato administrativo por naturaleza en la Ley 30/2007}

Los mayores aciertos de la LCSP están en la incorporación de todo tipo de técnicas para racionalizar las adquisiciones de bienes y servicios (acuerdos marco, sistemas dinámicos de adquisición y centrales de compras), y fundamentalmente en la opción por la plena inserción de los medios electrónicos, informáticos y telemáticos en el ámbito de la contratación pública, con la definición del perfil del contratante. Y en las novedades técnicas que incorpora generalizadamente para todos los entes del sector público ${ }^{81}$, incluidas las técnicas de la subasta electrónica o los instrumentos para la racionalización de la contratación.

Aunque la personalidad de la LCSP, sin lugar a dudas, está en su particular estratificación de los entes del sector público: Administraciones Públicas, Poderes Adjudicadores con forma mercantil, y resto de las Entidades y Sociedades de titularidad pública, y en la regulación de las figuras contractuales del sector público con carácter general, al margen del contrato administrativo. De tal manera que, cuando han transcurrido más de 150 años desde la publicación de la primera Ley de la Jurisdicción Contencioso-Administrativa, y más de 40 desde la primera Ley de Contratos del Estado, la nueva regulación certifica el abandono del contrato administrativo como figura central de la contratación pública, -en cierto sentido, se vuelve a la situación inicial de indiferencia conceptual-, y como entonces, el contrato administrativo ya no cuenta en la LCSP con un concepto propio y específico, sino con el general aplicable a todo el sector público, y tampoco tiene asociados los procedimientos de contratación, que se regulan por separado para todo el sector público; sólo se justifica en la necesaria salvaguardia del interés público que le corresponde a la Administración, pero ya no identifica una regulación propia, ahora limitada a regular el juego de las cláusulas exorbitantes.

81 DICTAMEN DEL CONSEJO DE ESTADO al proyecto de la Ley 30/2007 establece al efecto: «El anteproyecto de Ley de Contratos del Sector Público pretende un nuevo enfoque en la legislación de contratos públicos, que, poniendo término al sistema de sucesivas extensiones impuestas por las exigencias comunitarias, construya desde el principio el sistema de reglas jurídico-públicas partiendo de una perspectiva amplia. Tal planteamiento supone, en primer lugar, una delimitación inicial del ámbito de aplicación en términos más comprensivos (contratos del sector público), pero gira sobre todo alrededor de la pretendida asunción —se verá que no sin problemas - de un criterio funcional, impuesto por el Derecho comunitario, para la exigencia de regímenes contractuales diversos según que los contratos celebrados por entes del sector público se encuentren o no sujetos a regulación armonizada». 
Por otro lado, la omisión de una regulación uniforme de todos los procedimientos de contratación de todos los poderes adjudicadores -por dejado de los umbrales armonizados-, y su remisión a unas instrucciones internas de contratación, evidentemente sujetas a la discrecionalidad del control político, aunque supone una mejora sobre la situación anterior limitada a una mera declaración programática, deja abierta la posibilidad de una regulación general por cada Comunidad Autónoma de la contratación de sus poderes adjudicadores y sus medios propios con forma mercantil por debajo de los umbrales armonizados, que puede extenderse a la regulación de las empresas locales de gestión de servicios públicos que se regulan en los Arts. 85 y 86 de la Ley $7 / 85$, de 2 de abril, por el momento a resultas de las normas de contratación que los Gobiernos locales establezcan o aprueben en estas sociedades. 
$r_{e}$ ALA

II. JURISPRUDENCIA 
